\title{
México: gobernabilidad y normalidad electoral (1988-1998)
}

Víctor Manuel Reynoso

El Colegio de Putbla

\begin{abstract}
Análisis de los principales cambios en el sistema electoral y de partidos en 1988-1998 y sus efectos en la gobernabilidad desde tres perspectivas: aparición de nuevos actores partidarios o de nuevas funciones para los viejos; presencia, por primera vez, de gobiernos divididos a nivel local y nacional, y la reforma electoral de 1996. La tesis es que, a pesar de lo radical de los cambios que han dado lugar a un sistema electoral y de partidos distinto al que imperó en el país por décadas, la gobernabilidad se ha mantenido.
\end{abstract}

\section{INTRODUCCIÓN}

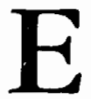

n los últimos diez años se han dado en México importantes cambios en materia electoral. A pesar de su lentitud y de que no haya, a diferencia de lo que ocurre en otros sistemas políticos, un hecho "fundacional" a partir del cual pueda decirse que tenemos un cambio de sistema electoral y de partidos, la realidad electoral mexicana de hoy es muy distinta a la de hace diez años.

Este texto analiza algunos de estos cambios, centrándose en la cuestión de los riesgos de ingobernabilidad que implican. Señala tres procesos: los nuevos actores, o los nuevos papeles para los viejos actores; los gobiernos divididos tanto a nivel regional como nacional, y finalmente la reforma política de 1996, calificada por algunos como "definitiva" (comillas incluidas).

El nuevo escenario trajo no sólo nuevos actores, sino nuevos papeles para actores que tenían ya varias décadas en la escena política mexicana. Destaca la aparición del Partido de la Revolución Democrática, formado por la unión de diversos grupos de la izquierda mexicana y una escisión del PRI. 
Esta aparición, producto de la notable fuerza que adquirió la candidatura presidencial de Cuauhtémoc Cárdenas en 1988, cambió el lugar de las demás fuerzas partidarias. Al PRI le significó un importante reto, pues revivió uno de los fantasmas que le han amenazado desde su origen: las escisiones. El PRD no sólo significa un importante desafío electoral; amenaza la unidad misma del otrora partido hegemónico.

El Partido Acción Nacional, por su parte, perdió con la aparición del PRD su lugar de principal oposición, o más bien, de oposición "casi única". Con lo que cambió la estrategia antisistema que lo había caracterizado en los años anteriores a la exitosa candidatura de Cárdenas.

Parte del cambio es que la oposición en México dejó de ser permanente. La alternancia en las elecciones locales mexicanas y la pluralidad en los congresos de los estados empezaron a ser una realidad. Lo que dio lugar a los llamados gobiernos divididos: el ejecutivo en manos de un partido que no tiene mayoría en el legislativo. Las elecciones de julio de 1997, las más competidas en la historia de las elecciones para el Congreso en la historia del país, dieron lugar a un gobierno federal dividido: el partido en el ejecutivo, el PRI, perdió la mayoría absoluta en el Congreso.

Previo a este importante cambio, y antecedente del mismo, hubo una importante reforma electoral que acabó de romper viejos equilibrios. Después de ella el control electoral por una sola fuerza política es difícil, al menos por la vía legal.
Todos estos cambios significan desafíos a la proverbial gobernabilidad que caracterizó a la política mexicana durante 60 años. ¿Podría mantenerse la gobernabilidad una vez que los rasgos fundamentales del sistema hegemónico desaparecieron? Un país en el que hubo durante seis décadas un partido "casi único", eseguiría siendo gobernable cuando la oposición dejara de serlo y ocupara importantes lugares en los ejecutivos locales? ¿No estaría en riesgo la gobernabilidad cuando ese partido perdiera la mayoría en la Cámara de Diputados federal?

A todas estas preguntas la realidad les ha dado respuesta. Respuestas provisionales, como todo en la historia humana. Y ellas son el motivo de este análisis.

\section{NUEVOS ACTORES}

El desenlace de las elecciones presidenciales de 1988 dio lugar a un nuevo escenario, a nuevos actores, y a nuevos papeles para los viejos actores. La causa que generó esta diversidad de efectos fue el éxito, notable e inesperado, de la candidatura de Cuauhtémoc Cárdenas a la presidencia de la república. El primer efecto fue el surgimiento de una nueva fuerza política, el "neocardenismo", que daría lugar a partir de mayo de 1989 a un nuevo partido, el de la Revolución Democrática.

El segundo, desplazar al Partido Acción Nacional como segunda fuerza electoral en el país. Durante más de 30 años el panismo había ocupado invariablemente ese lugar. El neocardenismo en la elección de 1988 lo 


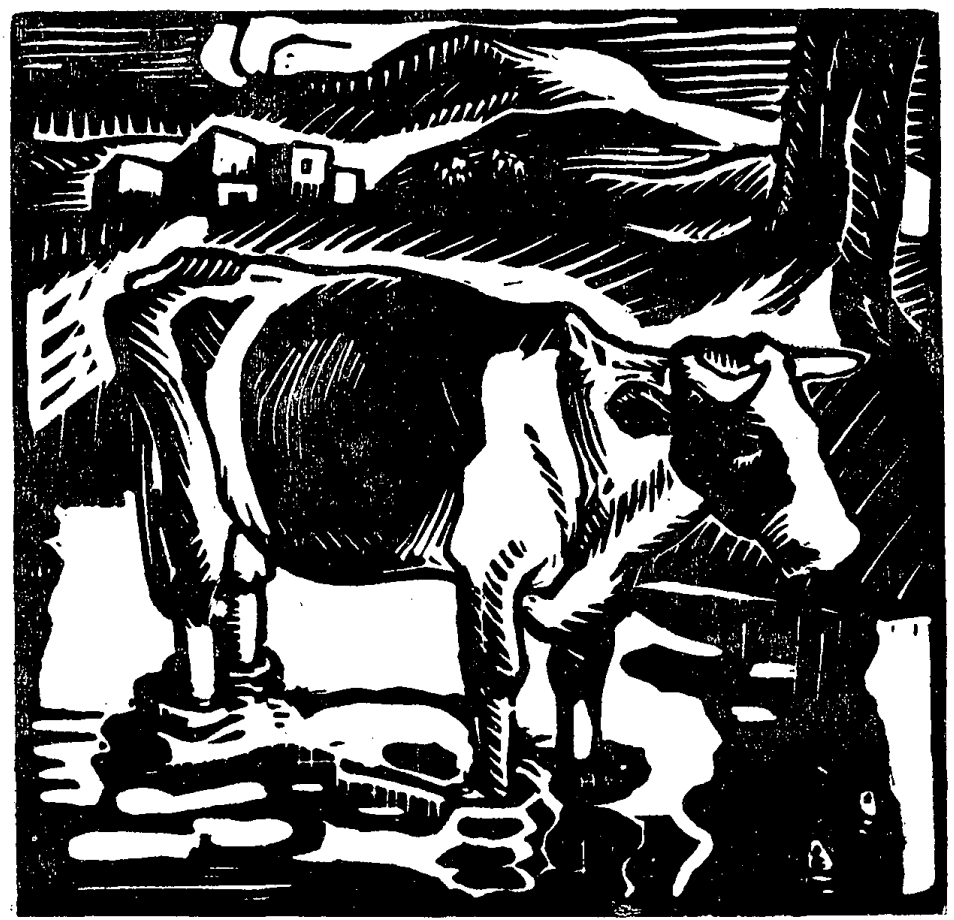

desplazó, con lo que cambió el lugar y la estrategia panistas.

Un tercer efecto tiene que ver con el impacto que la candidatura de Cárdenas tuvo en el Partido Revolucionario Institucional. Como todo partido hegemónico, su funcionamiento se basaba en una regla clara: la prohibición de la "salida" del mismo. El PRI coincidió durante varias décadas con la clase política por una razón: fuera de este partido, no había posibilidades de éxito. Es decir, la salida estaba inhibida de facto. De hecho, durante los años cuarenta y cincuenta, concretamente en las elecciones presidenciales de 1940, 1946 y 1952, el partido hegemónico encontró importantes desafíos electorales en candidatos que habían salido de sus filas. Aprendió la lección, y desde 1952 logró evitar escisiones que se convirtieran en candidaturas opositoras.

Era una regla de oro difícil de mantener. Dejando de lado que exigía el control electoral para no incentivar las escisiones (otra regla de oro: los candidatos del PRI siempre ganan, los de 
la oposición siempre pierden), no era sencillo mantener unido un partido tan grande numéricamente y tan amplio ideológicamente como el PRI. EI hecho de que tanto el control electoral como la unidad priista se hayan mantenido durante cinco elecciones presidenciales (treinta años) es una de las peculiaridades más notables de la vida política mexicana.

Creo que el significado más importante de la candidatura cardenista es ese: rompió la regla de oro de la unidad priista. Más que un hecho apuntaba a un cambio institucional, a un cambio en las reglas de juego del sistema electoral y de partidos: los priistas tendrían abierta la puerta de salida y podrían contender contra el otrora partido hegemónico.

En estrecha relación con lo anterior, el éxito de la candidatura de Cárdenas en 1988 cimbró otro de los pilares institucionales del sistema: el control electoral. Éste fue posible todavía en esa elección, pero resultó fuertemente cuestionado. Ninguno de los dos candidatos perdedores aceptó los resultados electorales. La de 1988 es la elección presidencial más cuestionada de la historia contemporánea de México. Los cambios eran urgentes.

Todo lo anterior estuvo acompañado de contenidos ideológicos. El neocardenismo critica al PRI no sólo por antidemocrático, sino por su proyecto económico, caracterizado como neoliberal. Proponía un proyecto económico y de nación con una mayor participación del Estado y orientado a favorecer a las mayorías. La de Cárdenas y sus seguidores fue una escisión por la izquierda, por lo que fue congruente que el PRD, fundado menos de un año después de la elección de 1988, tomara el registro del más importante partido de la izquierda mexicana, el Partido Mexicano Socialista. ${ }^{1}$

Al perder su sitio como principal oposición y ante el surgimiento del PRD, el PAN cambió la estrategia que había ido consolidando en los años ochenta. Desde 1983, y producto de lo que consideraba fraudes electorales que lo perjudicaban, el panismo fue orientándose hacia estrategias "antisistema" cada vez más radicales, que culminaron con la elección de Luis $\mathbf{H}$. Álvarez como presidente del partido y de Manuel J. Clouthier como candidato a la presidencia. ${ }^{2}$ Desde 1958 no se veía una campaña panista tan crítica y radical.

Pero ante el cambio de circunstancias, el PAN cambió. En 1989 se encontró por un lado con un aliado fácil: el gobierno del presidente Carlos Salinas. Fácil por un lado porque tenía qué ofrecerle en un intercambio político. Fácil porque estaba más cerca del PaN en su proyecto económico y político. Fácil porque buscó el apoyo panista, indispensable para adquirir una legitimidad que no tuvo en la elección y para realizar reformas a la Constitución, pues su partido no tenía en el

\footnotetext{
${ }^{1}$ Con ese nombre, el pMs había participado sólo en una elección. Pero había tomado el registro del Partido Socialista Unificado de Méxi$c o$, que a su vez continuaba al Partido Comunista Mexicano, existente desde 1919, aunque con registro legal a partir de 1977.

${ }^{2}$ Molinar, Tiempo, 1991; Reynoso, "Prueba", 1994.
} 
Congreso la mayoría calificada necesaria para hacerlo. ${ }^{3}$

Por el otro lado al panismo se le presentaba la posibilidad de una alianza con el Partido de la Revolución Democrática. Había bases objetivas para la misma: dos partidos de oposición que compartían el interés por un reforma electoral que diera mayores garantías de respeto al voto. Pero otras razones hacían del PRD un aliado difícil para el PAN. Ideológica y políticamente el perredismo estaba más alejado del panismo que el PRI. El nuevo partido representaba para el PAN la parte más negativa del PRI, y se referían a él como "el ex PRI","o el PRI fuera del poder".

No sólo veían en los dirigentes perredistas la encarnación del estatismo y la corrupción que caracterizaron, a juicio de los panistas, al PRI durante décadas, sino incluso los acusaban de haber sido partícipes del fraude electoral. ${ }^{4}$ El panismo vio en el perredismo una encarnación del sistema al que habían combatido desde su fundación, y en el gobierno de Salinas la posibilidad de un cambio.

Claro que además de los perfiles ideológicos y políticos estaban las posibilidades de intercambio político. Con el PRD había poco que intercambiar. El gobierno de Salinas, por el contrario, tenía cosas que ofrecer al

\footnotetext{
${ }^{3}$ Para reformar la Constitución Política de los Estados Unidos Mexicanos se requieren las dos terceras partes de los votos. Por primera vez en su historia, el PRI no tenía esa mayoría, pues apenas superó $50 \%$ de los diputados.

${ }^{4}$ Hasta hoy, todos los presidentes nacionales del PRD han sido ex priistas: Cuauhtémoc Cárdenas, Roberto Robles Garnica, Porfirio Munoz Ledo y Manuel López Obrador.
}

panismo a cambio del apoyo político que le era indispensable.

$\mathrm{Y}$ el intercambio se dio, en lo que fue uno de los aspectos más polémicos de la relación entre el PAN y el gobierno durante el salinismo. Los dirigentes panistas habían abierto esta posibilidad, cuando señalaron que Salinas, ante su carencia de legitimidad electoral, podía obtener una "legitimidad secundaria": dado que no tenía legitimidad en su origen, debía lograr la legitimidad en su ejercicio. A partir de esa concepción, los dirigentes panistas se entrevistaron con el cuestionado presidente de la república el 3 de diciembre de 1988. Exigían una reforma electoral y limpieza en los comicios locales.

Y el primer capítulo de este intercambio se dio en la reforma electoral de 1989. La reforma terminó en octubre de ese año. Suscitó una fuerte polémica. Si bien creo exagerado afirmar, como lo hicieron algunos de sus críticos, que se trató más bien de una "contrarreforma", sí es cierto que consistió en un avance tibio, insuficiente. Tanto que después de ella habrían de darse dos más en el sexenio de Salinas (1988-1994), que todavía resultaron insuficientes, por lo que el gobicrno de Zedillo (1994-2000) se inició con una invitación a la reforma electoral.

Pero tener una reforma electoral insuficiente en México no constituía ninguna novedad. La novedad en 1989 fue que nunca antes se había presentado una coyuntura tan favorable para la oposición para exigir y lograr una reforma electoral a fondo, que posibilitara la existencia de elecciones competitivas. El PAN, señalaron los críticos, 
se conformó con poco; negoció este conformismo a cambio de algo.

Durante todo el sexenio el PAN fue criticado, fundamentalmente por los perredistas, de realizar negociaciones oscuras con el presidente Carlos Salinas. La primera sería el apoyo panista a la timorata reforma electoral de 1989. ¿Qué recibió el PAN a cambio? Quizá el reconocimiento a su triunfo electoral en Baja California, que tuvo lugar a mediados de ese mismo año.

Desde entonces todos, o casi todos, los triunfos electorales del PAN fueron criticados por el perredismo de ser producto de negociaciones ilegítimas. Se acuñó incluso un término: concertacesión. Concertar y ceder: negociar en la oscuridad, intercambiar, generalmente, reconocimiento a triunfos electorales por apoyo político al gobierno salinista.

Esta tesis de las concertacesiones se vio reforzada por el contrastante trato que tuvo el gobierno hacia el PRD. Nada concertó con él, nada le cedió. En justicia, hay que señalar que fue una relación recíproca: mutuamente correspondida. A diferencia del PAN que, reconociendo que Salinas no tenía una "legitimidad de origen", es decir, que las elecciones por las que había llegado al poder eran ilegítimas, pero que le ofrecían la posibilidad de adquirir una legitimidad "en el ejercicio" de su gobierno, el PRD no le concedió nada a Salinas. Siempre lo consideró ilegítimo a secas, sin matices. Salinas le correspondió al perredismo puntualmente.

La cuestión de las concertacesiones, la más clara de las cuales fue la elección para gobernador en Guanajuato en julio de 1991, merece un comenta- rio. Veamos el caso de Guanajuato. Ahí contendió un importante líder panista, Vicente Fox, contra un priista gris y desprestigiado, Ramón Aguirre. Porfirio Muñoz Ledo fue candidato del PRD, pero la lucha se dio entre los dos primeros.

Se dio un formato más o menos clásico en las elecciones en un sistema de partido hegemónico: el partido en el poder gana; la oposición alega fraude y moviliza a sus simpatizantes. Es entonces cuando viene la concertacesión: una solución supralegal y supraelectoral (o infralegal e infraelectoral, si se quiere): el candidato triunfador (priista) se retira; no se le concede el triunfo a quien quedó en segundo sitio, en este caso el candidato panista, sino a otro panista que ni siquiera contendió: Carlos Medina Plasencia. Desde entonces Guanajuato tuvo un gobernador no electo, sino concertacesionado.

La solución recibió muchas críticas. Generó descontentos en todas las partes: en los priistas, porque sentían que mediante una negociación les habían robado una elección en la que habían ganado; en los panistas, que consideraban que sólo habían logrado una "reparación parcial del daño"; en los perredistas, que veían una oscura alianza PRIPAN que los dejaba fuera y que alejaba la presencia de elecciones democráticas.

Fue por lo mismo una solución de transición, que no podía convertirse en regla. Hay que aclarar que no se utilizó sólo para el PAN: también fueron sacrificados candidatos priistas, supuestamente ganadores, en Michoacán y en San Luis Potosí; en el primer caso el candidato era un perredista y en el segundo una coalición que apo- 
yó la candidatura del carismático Salvador Nava.

Ciertamente las concertacesiones no eran soluciones democráticas. Pero tampoco estaban ajenas a la realidad electoral. Si el gobierno federal priista cedía, o "concertacesionaba", era porque estaba frente a una fuerza electoral considerable, que podía alegar, con argumentos razonables, que había habido fraude, y que podía movilizar a sus simpatizantes. Tal fue el caso del panismo en Guanajuato, del perredismo en Michoacán y del navismo en San Luis Potosí. No eran simples arreglos cupulares: eran negociaciones entre fuerzas electorales reales, en un país en el que el respeto al voto era algo todavía cuestionable.

La constrastante relación entre el gobierno de Salinas con los panistas por un lado y con los perredistas por el otro se debió en parte a la necesidad del PRI de cerrar la puerta de salida de su partido, en parte a la distinta estrategia del panismo y del perredismo hacia el gobierno y también influyó la cuestión ideológica. El PAN estaba más cerca de Salinas en programa e ideología que el PRD. El panismo incluso habló mucho de lo que consideraba su "victoria cultural": las tesis panistas no habían cambiado desde la fundación del partido en 1939, mientras que los grupos representados en el PRD y en el PRI habían cambiado sus principios para acercarse a lo que desde entonces planteaba el PAN. Básicamente se referían a la reivindicación de la democracia electoral y a la crítica al estatismo.

Con el gobierno de Zedillo las cosas cambiaron. Se acabó el mutuo encono gobierno-PRD. Y no es que cam- biaran su ideología y programas: cambiaron las actitudes políticas, por decirlo de alguna manera. La culminación de esta nueva relación entre el gobierno y el perredismo se dio en el reconocimiento del triunfo de Cuauhtémoc Cárdenas en la elección de gobernador del Distrito Federal en julio de 1997, y en la relación institucional que dicho gobierno ha tenido con el presidente de la república.

En el gobierno zedillista se ha consolidado la normalidad democrática, entendida como la realización de elecciones cuyo resultado es aceptado por los participantes. Esta normalidad ha dado lugar a una relación más institucional y menos discrecional entre los actores políticos. Ya no hay un partido con tácticas antisistema, como fue el PRD el sexenio pasado; ni otro con actitudes prosistema, como fue el panismo. Ya no se habla de concertacesiones electorales. Pocas han sido las elecciones cuestionadas, cuando eran la regla en el gobierno pasado.

La distinción entre los actores políticos es ahora otra. Ya no se trata tanto de un actor en el gobierno, y otros en la oposición. Los tres principales partidos ocupan importantes posiciones de gobierno a nivel local. Lo interesante sería hacer un análisis de los mismos en su forma de gobernar. ¿Hay algo que distinga a los gobiernos panistas, a los perredistas, a los priistas? ¿Hay claras diferencias partidarias en las formas de gobernar? ¿Es válida la distinción entre izquierda, centro, derecha, para clasificar las formas de gobierno de estos partidos? Preguntas trascendentes, pero que desbordan estas páginas. 
GOBIERNOS DIVIDIDOS: NUEVAS RELACIONES ENTRE LEGISLATIVO Y EJECUTINO

\section{La tradición mexicana}

La tradición mexicana en las relaciones entre el poder legislativo y el ejecutivo, hasta antes de 1989 , es interesante. Por un lado, en lo que se podría llamar la "tradición inmediata" (al menos las últimas cinco décadas) es notablemente consistente en la subordinación del legislativo al ejecutivo. Desde 1936, por lo menos, las cámaras de diputados o senadores nunca se opusieron públicamente al poder ejecutivo.

La mayoría de los diputados y senadores pertenecieron en este periodo al mismo partido del presidente, lo que explica en parte la subordinación. Otra parte de la explicación está en la subordinación del partido al presidente, y no al contrario. Un mecanismo que permitió además la subordinación de los legisladores al partido y al presidente en última instancia fue la prohibición de reelección inmediata: les impedía hacer carrera parlamentaria, y los subordinaba a la organización partidaria y al ejecutivo. ${ }^{5}$

El hecho es que el sistema político mexicano, en la dilatada época de sistema de partido hegemónico, vivió gobiernos notablemente unificados, entendidos como la estrecha colaboración, subordinación incluso, entre el poder legislativo y el ejecutivo.

\footnotetext{
'Cosío Villegas, Sistema, 1976, p. 29; Pantoja "Gobierno", 1997, p. 6.
}

Viendo la historia del país en el largo plazo las cosas son distintas. Hay una tradición contradictoria, de consecuencias trágicas, que puede explicar en parte el modelo de gobierno unificado. En la historia mexicana hay al menos dos épocas notables por la fortaleza del Congreso, y en consecuencia por su enfrentamiento con el presidente de la república: durante las presidencias de Benito Juárez (1861-1862 y 1867-1872) y de Francisco I. Madero (1912-1913).

Ambas fueron experiencias breves. La relación de Juárez presidentc con el legislativo concluyó primero con la intervención francesa y luego con la muerte del presidente. El desenlace político fue el porfiriato: un presidencialismo de facto, que subordinó al legislativo hasta casi anularlo. Esta subordinación ha sido vista como una reacción frente a las dificultades que se vivieron durante el "gobierno dividido" en la época de Juárez:

la beligerancia del Congreso y la ausencia de una mayoría juarista en él daban lugar al cambio incesante de ministros; las discusiones estériles para el bien público y sólo provechosas para las aspiraciones particulares; las vejaciones a los ministros hechas por algún diputado $\mathrm{y}$ las escenas deplorables en las que paclecían la dignidad y el crédito del legislativo y el ejecutivo con ocasión de algún interés particular y grave perjuicio del interés público. ${ }^{6}$

El desenlace de la segunda experiencia fue más trágico. Se trató de un caso extremo de ingobernabilidad,

${ }^{6}$ Pantoja, "Gobierno", 1997, p. 5. 
que culminó con un golpe de Estado, el asesinato del presidente y el vicepresidente, y una guerra civil. Fueron los breves años del gobierno maderista, en donde la oposición al ejecutivo predominó en las dos cámaras. Se trataba por un lado de los intentos de restauración del porfiriato y por otro de propuestas revolucionarias más radicales que las de Madero. ${ }^{7}$

En la "tradición inmediata", en la que el gobierno se unifica vía la subordinación del legislativo al ejecutivo, puede verse una reacción a estas experiencias históricas. Tanto dicha tradición como las experiencias presentan interesantes desafíos, a la práctica política por supuesto, pero también a la explicación e interpretación históricas. ¿Fracasaron las experiencias de gobiernos divididos en el pasado mexicano por razones circunstanciales o "estructurales"? ¿Qué tan presentes están esas razones hoy en día? Puede que estructuras de larga duración, como la cultura política, sigan entre nosotros y hagan más recomendable una unificación de gobiernos. Puede que las cosas hayan cambiado (el país es muy distinto en muchos aspectos a como era en 1913) y que la situación que dio al traste con la división de poderes de facto ya no esté entre nosotros.

La ruptura de la tradición: gobiernos divididos en entidades federativas desde 1989

En 1989 , por primera vez en la historia del sistema de partidos contempo-

${ }^{7}$ Ibid. ráneos en México, un partido de oposición ganó una gubernatura. El Partido Acción Nacional derrotó al PRI en el norteño estado de Baja California. A esta novedad la acompañó otra: ningún partido tuvo la mayoría absoluta (50\% más uno) en el Congreso local. El PAN obtuvo $47 \%$ de las curules, el PRI 32\% y otros cuatro partidos, 5\% cada uno. ${ }^{8}$ En el ámbito local empezaba la alternancia en el ejecutivo por un lado y los "gobiernos divididos", o "no unificados" por el otro.?

Si estas novedades tardaron varias décadas en llegar, una vez iniciadas crecieron rápidamente. Entre 1989 y 1997 hubo alternancia en once entidades federativas, incluida la capital del país. Se dieron además trece casos de gobiernos divididos, a un ritmo creciente (véase cuadro 1).

De tal manera que para fines de 1997 se tenían o se habían tenido experiencias de este tipo de gobiernos en más de una tercera parte de las entidades del país. ${ }^{10}$ No es todavía una regla, pero ya no es una excepción.

Hay que subrayar la novedad de estas experiencias respecto a las tradiciones mexicanas. Prácticamente fueron inexistentes en la época posrevolucio-

${ }^{8}$ Lujambio, Poder, 1996, p. 22.

9 Alonso Lujambio define gobierno dividido como "aquel en el que, en el marco de un régimen de división de poderes, el partido que llevó al presidente (o al gobernador) a ocupar la titularidad del poder ejecutivo no cuenta con el control mayoritario, esto es, por lo menos con $50 \%+1$ de los escaños en la Asamblea Legislativa", Ibid., p. 9

${ }^{10} \mathrm{De}$ los trece casos dos tuvieron lugar en distintas legislaturas de la misma entidad: Baja California y Guanajuato. Ver Lujambio, Poder, 1996, y Hurtado, “Gobiernos”, 1998. 
Cuadro 1. México. Número de gobiernos divididos en entidades federativas por año

1989: 1 1990: 0 1991: 1 1992: 1 1993: 1 1994: 1 1995: 2 1996: 2 1997: 4

Fuente: Hurtado, "Gobiernos", 1998, p. 48, cuadro 2.

naria, o al menos en la época del sistema de partido hegemónico. Los gobiernos divididos tienen problemas en sí mismos, en cualquier tiempo y lugar. Pero en México estos problemas, sintetizados en el término un tanto ambiguo de ingobernabilidad, se acentuaban por las dos tradiciones a las que hemos hecho referencia: por un lado la ya citada de unificación y subordinación casi total de los legislativos al ejecutivo; por otro, recuerdos de las experiencias de Juárez y Madero, lejanas pero preocupantes para quienes no cierran los ojos a la historia.

¿Cuál es el balance? ¿Ha habido crisis de ingobernabilidad en las entidades con gobiernos divididos? ¿En qué han consistido dichas crisis? ¿Qué las explica? En los casos donde no han existido, ¿qué explica su ausencia? La ingobernabilidad no es ciertamente la única expectativa para un gobierno dividido. Hay también escenarios positivos: fortalecimiento del poder legislativo y por tanto de la división de poderes y enriquecimiento de la vida parlamentaria. En el balance hay que tener en cuenta también en qué proporción se han cumplido estas expectativas positivas.

Afortunadamente contamos con investigaciones que den cuenta de este balance. Fundamentalmente el libro de Alonso Lujambio, que presenta cinco estudios de caso realizados por destacados investigadores. Ahí se analizan las primeras experiencias de gobiernos divididos en los estados mexicanos: Baja California, Guanajuato, Chihuahua, Baja California Sur y Aguascalientes. ${ }^{11}$

Las investigaciones del libro muestran que los gobiernos divididos, con toda su novedad para la tradición política mexicana, no han dado lugar a la catástrofe. Sí ha habido mayores conflictos tanto en el interior del legislativo como entre este poder y el ejecutivo. Ha habido lo que con optimismo podríamos llamar "costos de aprendizaje": los conflictos, sobre todo los que paralizan o retrasan el trabajo legislativo, se han dado en las primeras experiencias o en los primeros meses de las mismas.

Pero estos mismos conflictos pueden ser vistos de otra manera: como una dinamización de la vida parlamentaria. Si bien la actividad legislativa, entendida como el número de decretos o resoluciones aprobadas, no se ha incrementado, sí ha aumentado la discusión de las mismas. Lo que anteriormente era un trámite -aprobar las propuestas del ejecutivo, tanto en lo que se refiere a nuevas leyes, reformas a las anteriores, aprobación de cuentas pú-

${ }^{11}$ El libro (Lujambio, Poder, 1996) abarca cinco entidades y siete legislaturas (Baja California y Guanajuato tienen dos legislaturas con gobiernos divididos cada una). Faltan algunas surgidas durante o después de la publicación del libro: México y Coahuila (1996), Morelos, Distrito Federal (1997). 


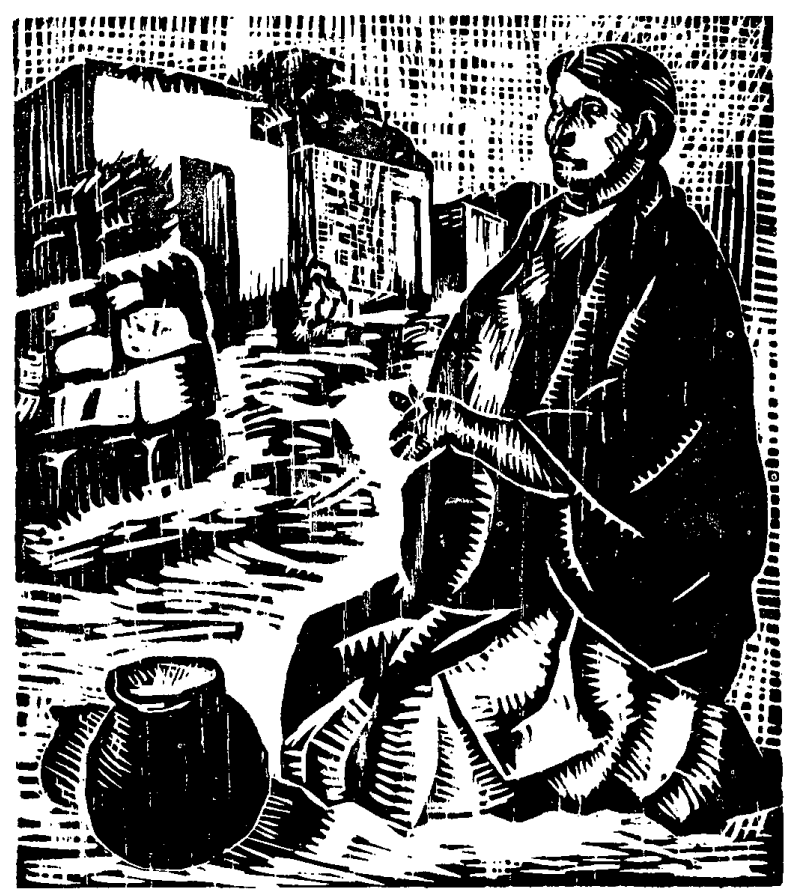

blicas o de presupuestos- es ahora motivo de mayor análisis y discusión.

Como consecuencia, el presupuesto de los congresos ha aumentado notablemente. Y en general el costo de la política, que en México ha aumentado no sólo en lo que se refiere a los congresos, sino en general con la transición a la democracia, ${ }^{12}$ un dato que

12 Guillén, “Gobierno", 1996, p. 44, llama acertadamente la atención sobre este punto. No explicita otros costos, pero entre ellos hay que tener en cuenta el creciente financiamiento público a los partidos políticos y el también cre- hay que tener en cuenta pues si los costos superan a los beneficios hay algo que revisar.

Pero antes de continuar con el balance hay que señalar que no todos los gobiernos divididos son iguales. Bajo este término se entiende una situación general con casos particulares diversos entre sí:

se entiende aquí por gobierno dividiclo aquel en el que, en el marco de un ré-

ciente costo de los organismos electorales, tanto el Instituto Federal Electoral como los organismos electorales locales. 
gimen de división de poderes, el partido que llevó al presidente (o al gobernador) a ocupar la titularidad del poder ejecutivo no cuenta con el control mayoritario, esto es, por lo menos con $50 \%$ más uno, de los escaños de la Asamblea Legislativa. $^{13}$

E1 mismo Lujambio establece una tipología de este tipo de gobiernos: primero aquellos en los que el partido en el ejecutivo tiene $50 \%$ de las curules, donde es una "casi-casi mayoría"; un segundo tipo se caracteriza porque el partido gobernante es la minoría más grande en el legislativo, es decir, tiene la mayoría relativa; en el tercer tipo el partido del ejecutivo es una de las minorías en el Congreso; finalmente estaría el caso estricto de gobierno dividido, en el que la Asamblea Le. gislativa está dominada por un partido distinto al del poder ejecutivo (es decir, un partido opositor tiene la mayoría absoluta en el Congreso). ${ }^{14}$

Los riesgos y las posibilidades de los gobiernos divididos cambian en cada tipo. Dependen en parte de circunstancias particulares, pero en general en el primer tipo el partido en el ejecutivo tiene la posibilidad de encontrar "alianzas baratas": un solo voto de otro diputado que le dé la mayoría absóluta. En el otro extremo, cuando la mayoría la tiene otro partido, hay la necesidad de negociar de poder a poder.

Ya entrando al análisis de los casos, y además de la conclusión general de que estas nuevas experiencias en ningún caso han dado lugar al desastre,

${ }^{13}$ Lujambio, Poder, 1996, p. 9.

${ }^{14}$ Ibid. p. 18. parecen desprenderse varias conclusiones generales.

La primera es que en la mayoría de los casos hay un proceso de aprendizaje: en un principio, que en algunos casos dura meses y en otros años, prevalece el enfrentamiento entre los bloques parlamentarios, renuentes a cooperar. Pero en el mediano plazo las fracciones parlamentarias negocian entre ellas. El caso más interesante al respecto, quizá por ser el primero y el que más ha durado hasta ahora, es el de Baja California. En los seis años en que duró el gobierno dividido, se pasó del encono entre el PAN - el partido en el gobierno y la minoría más grande en dos legislaturas (1989-1992 y 1992-1995)- y el PRI, a un diseño de agenda legislativa que resumía los acuerdos de las fracciones parlamentarias de estos partidos. ${ }^{15}$

Lo interesante del caso, bien resaltado por Tonatiuh Guillén, es que mientras los bloques permanecieron enfrentados, el ejecutivo se fortaleció a costa del Congreso. El bloque parlamentario panista se alió con el gobernador de este mismo partido para enfrentar a la fracción priista. Una alianza de subordinación: de lo que se trataba era de sacar adelante el trabajo del gobernador Ernesto Ruffo. ${ }^{16}$ Por el contrario, cuando los bloques parlamentarios empiezan a negociar entre sí, y acuerdan una agenda de trabajo, la institución parlamentaria adquiere una fuerza y autonomía que no tuvo en la etapa anterior, de enfrentamiento.

\footnotetext{
${ }^{15}$ Guillén, "Gobierno", 1996.

${ }^{16}$ Ibid., pp. 51-52.
} 
En este estado del norte del país el proceso llevó cinco años, hasta el inicio de una nueva etapa, en la que el enfrentamiento se dejó atrás y se pasó al arte de la negociación:

$Y$ fue en este ambiente tenso como surgió[... ]una nueva etapa del trabajo legislativo, que constituye un paso más en la evolución de la negociación política interna de la institución. Por primera vez los partidos comenzaron a definir compromisos, avanzando en su reconocimiento mutuo como interlocutores, ampliando el espacio de la negociación. Ya no fue únicamente para definir bloques, sino para definir una agenda legislativa con preocupaciones comunes. Al mismo tiempo, al producirse un énfasis de la negociación política entre los partidos representados en el Congreso, en esa medida se redujo el peso del gobernador del estado. ${ }^{17}$

Además de este proceso de aprendizaje, llama la atención en los estudios de caso que los puntos de conflicto entre el ejecutivo y los congresos en gobiernos divididos son, por un lado, la fiscalización de las cuentas públicas y la aprobación de los presupuestos. En otros términos, la revisión de los gastos hechos por el ejecutivo el año anterior y la aprobación del proyecto de gastos para el año siguiente. Cuestión de dinero en ambos casos.

No es de extrañar que sea así. Por un lado la cuestión presupuestal es fundamental para cualquier gobierno; la manera más fácil de boicotearlo o al menos limitarlo es restringiéndole los recursos económicos. En el caso mexi-

${ }^{17}$ Ibid., p. 58. cano había, o hay, una importancia particular: la sospecha de desvío de fondos públicos hacia el patrimonio particular de los políticos por un lado, o hacia el partido en el poder por el otro.

En prácticamente todos los casos analizados los gastos públicos y el presupuesto de egresos ha sido un tema, o el tema, de la relación entre el poder ejecutivo y el legislativo. En general hay un aspecto positivo en esto: los gobiernos, estatales y municipales, deben tener más cuidado en la forma en que diseñan y realizan sus gastos, pues en gobiernos divididos hay mayor probabilidad de que sean fiscalizados.

En algunos casos hay peculiaridades que vale la pena resaltar. El más notable es el de Chihuahua, pues ahí, a fines de 1996, la mayoría priista en el Congreso, aliada al diputado del PRD, modificó el presupuesto del gobernador panista y éste recurrió a una medida extrema: vetó algunos de los cambios. En términos porcentuales los cambios hechos por la fracción priista no fueron sustantivos: abarcaron $0.7 \%$ de lo presupuestado por el gobernador. ${ }^{18}$ Pero son una manifestación de la dinámica que se ha vivido en ese estado, que desde 1995 tiene un gobierno dividido en el sentido más riguroso: un partido (PRI) distinto al del gobernador (PAN) tiene la mayoría absoluta en el Congreso.

La actividad legislativa en general y la aprobación del presupuesto en particular se volvió, a juicio del autor, una disputa por el capital político. Los diputados priistas preparaban con esa acti-

${ }^{10}$ Aziz, "Alternancia", 1996, p. 124. 
vidad la "restauración", es decir, el regreso al poder de su partido, que perdió por primera vez en 1992. ${ }^{19}$

Debido a esto Chihuahua es el caso más problemático de los cinco analizados. La "división del gobierno chihuahuense", que se dio desde 1995 y durará al menos hasta 1998, activó las expectativas negativas sobre este tipo de gobiernos. Una competencia por el poder que podríamos llamar "negativa", en cuanto genera más males que bienes públicos: de lo que se trata es de que el propio partido crezca a costa del adversario. Se intenta pues perjudicarlo o al menos limitarlo.

De cualquier manera se ha estado lejos de la catástrofe. En el análisis de Aziz está implícito además que ambos poderes han tensado sus fuerzas, se han esforzado por ser mejores. Una consecuencia de la competencia, aunque ésta no sea tan "civilizada" como se quisiera, ha sido un incentivo para las principales fuerzas políticas de la entidad.

Cabe señalar un "arreglo institucional" interesante, presente en la Constitución de Chihuahua y en las de otras cinco entidades del país: lo que Lujambio llama la verdadera cláusula de gobernabilidad. En general se entiende por cláusula de gobernabilidad la disposición legal de convertir a la principal mayoría simple en una elección en mayoría absoluta en el Congreso. La verdadera es distinta. Consiste en que, en el caso de que el Congreso no apruebe el presupuesto del ejecutivo, automáticamente tiene vigencia el presupuesto del año anterior. Esto evita la

${ }^{19} \mathrm{Ibid}$. parálisis, la posibilidad de que no haya presupuesto público.

Si la competencia y el no acuerdo fue la tónica en Chihuahua, en Baja California Sur, por el contrario, se llegó a la colaboración. Por una curiosa situación, de quince diputados sólo tomaron posesión, en la primera mitad de la legislatura, catorce; siete del PRI y siete del PAN. El gobernador era priista, pero el Pan gobernaba tres de los cinco municipios. Ambos partidos compartían pues el interés de no paralizar a los ejecutivos (estatal y municipales), lo que dio lugar a una lógica de cooperación. ${ }^{20}$

Ciertamente hubo conflictos en esa legislatura que llevaron varias veces a la movilización de la policía alrededor del recinto parlamentario e incluso al cambio de local del Congreso. Pero se debieron a una situación muy singular: el diputado número quince, Jaime Tuchman, no pudo tomar posesión, pues originó un conflicto, en parte legal y en parte político, al renunciar a su partido días antes de la elección, cuando ya no podía ser sustituido, y resultar electo. Después de algunas semanas muy agitadas -Tuchman despertó el encono de los panistas, que se negaron a que tomara posesión- se acordó que hubiera elecciones extraordinarias que ganó el PRI y que acabaron con el gobierno dividido. ${ }^{21}$

En el pequeño estado de Aguascalientes tuvo lugar también un gobierno dividido a partir de 1995. Ningún partido obtuvo la mayoría en el Congreso, el PAN obtuvo la minoría más

\footnotetext{
${ }^{20}$ Garmendia, "Gobierno", 1996, p. 161.

${ }^{21}$ Ibid.
} 
grande y el PRI la segunda. Después de un momento de tensión, entre la elección y la toma de posesión del nuevo Congreso, en el que los diputados de la legislatura anterior trataron de modificar la Ley Orgánica del Congreso para perjudicar a la próxima mayoría panista, esta entidad vivió una relación notablemente cordial entre ejecutivo y legislativo. ${ }^{22}$

Dos factores parecen haber intervenido en esta cordialidad. Por un lado lo que podríamos llamar el proceso de aprendizaje; en 1995 la experiencia de gobiernos divididos no era nueva, empezaba por el contrario a ser una regla a la que los partidos parecían acostumbrarse y aceptar. Por otro, un factor sin el cual no se explica lo anterior: la intervención del gobierno federal, concretamente la Secretaría de Gobernación, para promover la cooperación entre diferentes fuerzas políticas. ${ }^{23}$

No fue el único caso. Aziz señala esta "intervención mediadora de los poderes federales" como uno de los espacios de protección institucional para evitar la ingobernabilidad a la que pueden dar lugar los gobiernos divididos. ${ }^{24}$

Y quizá el caso más claro al respecto es el de Guanajuato. Ahí se han tenido dos legislaturas con gobiernos divididos "duros": el Congreso controlado por una mayoría absoluta distinta al partido del gobernador. Dos gobernadores panistas convivieron con legislaturas priistas. En un primer caso (1991-1994) predominó la tensión. En

${ }^{22}$ Reyes, "Gobierno", 1996.

${ }^{23}$ Ibid., p. 185.

${ }^{24}$ Aziz, "Alternancia", 1996, p. 122. el segundo (1994-1997), el acuerdo. Según Luis Miguel Rionda la diferencia se debió al oficio de Franciso Ruiz Massieu, operador del presidente Ernesto Zedillo. ${ }^{25}$

El factor gobierno federal es pues fundamental, no sólo en la convivencia en gobiernos divididos, sino en muchos otros asuntos de política regional que requieren de una instancia mediadora o de un agente central. El problema, como se verá más adelante, está cuando la división entre ejecutivo y legislativo se produce a nivel federal, y no hay una instancia superior tan clara que pueda mediar los intereses enfrentados.

Otro tema importante en la nueva composición de los congresos es la forma como se logran las mayorías. Tema excluido, al menos para las decisiones que exigen mayoría absoluta (50\% más uno), de los casos en los que un partido tiene esa mayoría en el Congreso (como Chihuahua y Guanajuato en los casos analizados). No es que la negociación esté excluida de ellos, pero se da en otras pistas, no en la construcción de mayorías legislativas.

El caso más heterodoxo al respecto es el de Baja California. En la primera legislatura con gobierno dividido (19891992) el PaN necesitaba un voto para la mayoría absoluta; en la segunda (19921995) requería dos votos. En el primer caso logró una alianza sistemática con un diputado del Partido Auténtico de la Revolución Mexicana, pequeña organización en vías de extinción que fue calificada por Cosío Villegas como

${ }^{25}$ Rionda, "Guanajuato", 1996, pp. 91 ss. 
un partido "más priista que el PRI". Era pues una alianza rara, que puede escandalizar a los ortodoxos: pocos puntos en común y muchas diferencias han tenido en su historia el PAN y el PARM. Pero fue una alianza que permitió la gobernabilidad y evitó que abortara la primera experiencia de gobierno de oposición y la división a nivel regional en el país. ${ }^{26}$

Pero la alianza en la segunda legislatura fue todavía más rara: entre la fracción panista y dos diputados priistas, miembros de una de las organizaciones corporativas del PRI, la Confederación Nacional Campesina. Se trata de uno de los sectores más conservadores, tradicionales y premodernos de ese partido. Su alianza con el modernizador PAN, representante de las clases medias urbanas, fue todavía más claramente un caso de pragmatismo político. Haría que los ortodoxos ideológicos se rasgaran las vestiduras, pero permitió el funcionamiento del Congreso y del primer gobierno panista a nivel estatal. ${ }^{27}$

Estas dos alianzas son, creo, algo más que curiosidades o fuentes para la lamentación sobre la incongruencia de los políticos. Muestran que la vida política cotidiana, en condiciones como las de gobiernos divididos, exige pensar más en las consecuencias de las acciones que en los principios doctrinarios abstractos. Desde el escritorio puede ser fácil criticar, pero desde la política práctica no hay de otra: hay que construir consensos para sacar las decisiones adelante.

${ }^{26}$ Guillén, "Golbierno", 1996, p. 50.

${ }^{27}$ Ibid., pp. 56 ss.
Muestran además algo más circunstancial e histórico: en este momento de la historia del país no es la ideología o la doctrina lo que está ordenando la política. No tenemos, indican este tipo de alianzas y actitudes, una política fuertemente ideológica; podrá haber otros hechos que indiquen lo contrario. Pero la práctica parlamentaria misma, las discusiones cotidianas, la necesidad de llegar a un acuerdo hoy y mañana a otro, la cercanía física entre adversarios incluso, favorece más al diálogo y al acuerdo que al enfrentamiento basado en posiciones políticas o ideológicas irreductibles. No hay nada que asegure que esto será así, pero al menos está dada la probabilidad.

El análisis de los gobiernos divididos que he revisado aquí partía de una preocupación: el riesgo de la ingobernabilidad. Preocupación compartida en la mayor parte de la bibliografía sobre el tema. ${ }^{28}$ Pero no todo en este tipo de gobiernos es riesgo; hay la posibilidad de dinamizar la política, de incentivar a los gobernantes y legisladores, de permitir una división de poderes que genere bienes públicos para la sociedad. Algunas de las conclusiones de los estudios de caso aquí presentados reconocen o destacan estos logros.

En varios casos se señala que la importancia de los congresos aumentó, medida en términos tan concretos como el presupuesto (Baja California, Guanajuato, Chihuahua y Aguascalientes). El aumento seguramente derivó en mejores ingresos para los diputados, pero también en mejores condi-

${ }^{28}$ Lujambio, Poder, 1996, pp. 10 ss. 
ciones y apoyo técnico para realizar su trabajo. ${ }^{29}$

Como muchas cosas en la vida, ese incremento tiene dos caras. Por un lado permite que los legislativos avancen de ser un "no-poder" a un verdadero poder que haga realidad la división de poderes. Por otro aumentan los costos de la política, que en nuestro país se han incrementado conforme avanza la transición a la democracia. $^{30}$

Otro signo, más cualitativo, de fortalecimiento legislativo son las reformas a las leyes orgánicas de los congresos. Se mencionan en varios de los casos estudiados, y van generalmente en el sentido de mejorar el diseño de las comisiones de trabajo internas, incluyendo la representación de las fracciones parlamentarias en ellas. Todo ello producto de la mayor pluralidad en las cámaras.

\section{La primera Cámara de Diputados federal dividida}

Hasta aquí el balance de las primeras experiencias de gobiernos divididos locales en México. Fueron el prefacio del primer gobierno dividido a nivel nacional, resultado de las elecciones federales del 6 de julio de 1997. Se trató en general de un preludio positivo: sin casos serios de ingobernabilidad y con predominio de la capacidad de negociar y establecer alianzas. Hubo además, al parecer, un proceso de 160.

${ }^{29}$ Garmendia, “Gobierno”, 1996, pp. 159 -

${ }^{30}$ Guillén, "Gobierno", 1996, p. 44. aprendizaje: de las tensiones en los primeros años en Baja California a la actitud notablemente conciliadora en Aguascalientes. Lo anterior es una conclusión general, no un dogma. En Chihuahua se dio a fines de 1996 la ma. yor tensión entre un legislativo y un ejecutivo; en el mismo Aguascalientes las tensiones aparecieron conforme se acercaban las elecciones federales.

Dos momentos pueden sintetizar lo que fue el primer periodo de sesiones de la primera Cámara de Diputados sin mayoría priista: la instalación de la misma y el Tercer Informe del presidente Zedillo por un lado, y la aprobación de la miscelánea fiscal por otro. Los primeros tuvieron lugar al iniciar el periodo, el 30 de agosto y el 1 de septiembre de 1997, respectivamente; el segundo al finalizar el mismo, en el mes de diciembre del mismo año.

Para comprender la importancia, simbólica y política, tanto de la instalación de la Cámara como del Tercer Informe presidencial, hay que tener en cuenta lo que habían sido las presentaciones de este tipo de informes en la tradición política mexicana. El presidente de la república tiene la obligación de asistir a la apertura de sesiones ordinarias del Congreso, y presentar un informe por escrito "cn el que manifieste el estado general que guarda la administración pública del país". ${ }^{31}$ Además de una obligación legal, el informe ha sido el principal ritual del presidencialismo mexicano. El titular del ejecutivo se presenta a la instalación anual del Congreso, con la

\footnotetext{
${ }^{31}$ Artículo 69 de la Constitución Política de los Estados Unidos Mexicanos.
} 
presencia de diputados y senadores, y generalmente con la del gabinete, el cuerpo diplomático, los principales líderes empresariales, en fin: el pleno de la clase política en el país.

Hasta 1988 se trató de un ritual presidencialista que expresaba con claridad que la política mexicana se centraba en la institución presidencial. A partir de ese año, debido a la cuestionada elección de Carlos Salinas, el ritual cambió. El presidente fue "interpelado" por la oposición; su informe ya no recibió sólo aplausos incondicionales, sino interrupciones que cuestionaban sus dichos. Aún así, o precisamente por eso, sigue siendo el principal acto político y simbólico de la vida política mexicana.

Después de que el presidente rinde su informe, un diputado, el presidente en turno de la mesa directiva de la Cámara, le da respuesta. Este rasgo del ritual sería fundamental en la instalación del primer Congreso sin mayoría priista, como se verá más adelante.

Después de las elecciones para diputados del 6 de julio de 1997, la Cámara quedó como se muestra en el cuadro 2.

El PRI quedaba con la mayoría relativa. Necesitaba doce votos para alcanzar la mayoría absoluta. Pero la oposición logró unificarse, en lo que se conoció como el Grupo de los Cuatro o G-4, y tuvo así la mayoría absoluta para instalarse sin los priistas y para nombrar a la mesa directiva y a su presidente.

Los priistas no estuvieron de acuerdo, y los últimos días del mes de agosto, cuando debía instalarse la LVII Legislatura, fueron de inusitada intensidad política. Buena parte de esa intensidad tuvo que ver con la figura del
Cuadro 2. Composición del la

LVII Legislatura (1997-2000) en agosto de 1997

$\begin{array}{lcc}\text { Partido } & \text { PRI } & \text { PRD } \\ \text { Curules } & 239(47.8) & 125(25) \\ & & \\ \text { Partido } & \text { PAN } & \text { PVEM } \\ \text { Curules } & 121(24.2) & 8(1.6) \\ & & \\ \text { Partido } & P T & \text { Total } \\ \text { Curules } & 7(1.4) & 500\end{array}$

Las cantidades entre paréntesis corresponden al porcentaje.

perredista Porfirio Muñoz Ledo, pues la oposición, el G-4, pretendía nombrarlo presidente de la mesa directiva, con lo que contestaría el informe presidencial.

A los priistas les parecía inaceptable. Muñoz Ledo fue un destacado priista; el más destacado sin duda de los que ahora militan en el PRD. Es, después de Cuauhtémoc Cárdenas, el principal líder de este partido. Para el PRI era una afrenta que llegara a ser el diputado que respondiera al informe, no por su importancia como líder opositor, sino por su pasado.

Durante el jaloneo de esos días, el PRI y el gobierno fueron acusados por la oposición de tratar de corromper, o cooptar, a diputados opositores para lograr los doce votos que necesitaban para tener mayoría absoluta. Concretamente se acusó al entonces secretario de Gobernación, Emilio Chuayffet, quien renunciaría meses después a consecuencia, en buena medida, de esas acusaciones. 
Pero la oposición logró mantenerse unida. La tensión fue tal, que la LVII Legislatura se instaló sin la presencia priista. El 30 de agosto, 255 diputados del G-4 instalaron la Cámara nombrando presidente para el mes de septiembre a Muñoz Ledo. Nada pudo hacer el PRI para impedir que éste respondiera al tercer informe presidencial, presentado el 1 de septiembre de 1997.

Durante los días que antecedieron al informe, los hechos de la Cámara de Diputados fueron acompañados de términos como "crisis constitucional", "desestabilización", "ingobernabilidad". Generalmente los priistas acusaban a la oposición de estar generando una crisis de ese tipo. El desconcierto cundió en el PRI. Las crónicas periodísticas de esos días dan cuenta del mismo. Un botón como muestra:

En los rostros se reflejaba el coraje, la impotencia y hasta la "rabia" porque "nos tienen aquí acuartelados, mientras la oposición hace de las suyas", decían. Otros más, mencionaron que "queramos o no vamos a bailar al son que nos toque la oposición". ${ }^{32}$

Debido a las tensiones y la incertidumbre que lo antecedieron, el informe presidencial cambió de formato. No se pudieron girar, con la debida anticipación, las invitaciones al cuerpo diplomático y otros distinguidos personajes. El informe no fue en la mañana, como había sido siempre, sino a las cinco de la tarde. Un desta-

${ }^{32}$ Francisco Arroyo, "Acto ilegal; posible, una crisis grave, dice Núñez", El Universal, 31 de agosto de 1997, México, D. F. cado opositor, Porfirio Muñoz Ledo, respondería al presidente. El G-4 había logrado torcerle el brazo al PRI.

¿Qué sucedió el 1 de septiembre de 1997, día en que Ernesto Zedillo presentó su tercer informe de gobierno, con todas estas novedades? Se cambió el horario, no asistieron los invitados especiales acostumbrados, el formato fue más sencillo. El presidente de la república presentó su informe por escrito y leyó un mensaje a la nación en una hora y media. El tono del mismo fue conciliador, llamando al diálogo, a la construcción de acuerdo, a la ética de la responsabilidad política y al respeto a las leyes y a las instituciones. Zedillo reconoció ante todo que las cosas habían cambiado, que había una nueva relación entre los poderes ejecutivo y legislativo. ${ }^{33}$

A pesar de todo, a los priistas no les quedó más que reconocer la nueva realidad. No intentaron, como lo habían señalado, boicotear la instalación de la Cámara ni la presentación del informe.

Muñoz Ledo dio respuesta con un discurso firme pero respetuoso. Resaltaba que el voto popular había dado lugar a la nueva conformación de la Cámara, y que era parte de la transición a la democracia en México. Esa transición es, a su juicio, parte importante de la agenda de la nueva legisla-

${ }^{33}$ Juan Arvizu Rioja, "Trabajar juntos, pide Zedillo al Congreso; diálogo, ofrece. Afianzar la normalidad democrática alcanzada el 6 de julio pasado, su reclamo. Definir de común acuerdo una renovada estrategia económica, planteó. Entregó al legislativo su III Informe", El Universal, 2 de septiembre de 1997. 


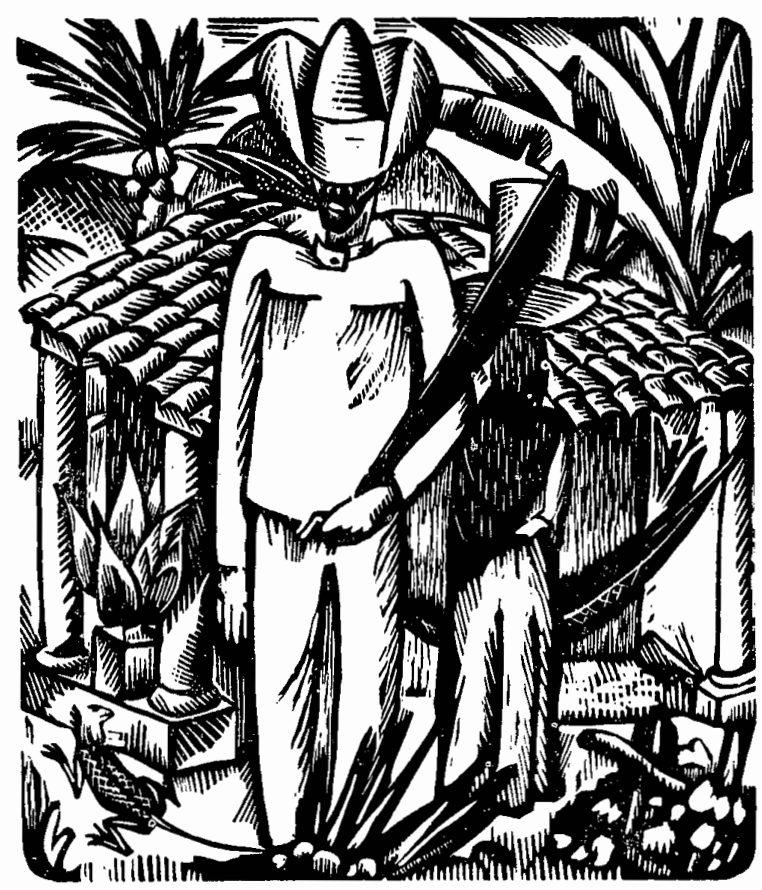

tura. Subrayaba la división de poderes, la crítica al poder absoluto y al autoritarismo. Insistía también en una nueva política de Estado que resolviera los problemas económicos de los mexicanos. $^{34}$

A pesar de los cambios y del conflictivo preámbulo que tuvo, la instalación del Congreso y el informe pre-

34 Véase la versión íntegra del mensaje de Porfirio Muñoz Ledo, que se publicó, entre otros, en El Universal el 2 de septiembre de 1997. sidencial de 1997 se llevó a cabo sin sorpresas ni interrupciones. El ritual parecía confirmar que las cosas habían cambiado, que había una nueva correlación de fuerzas en el país, que el priismo ya no era mayoría absoluta y que, con trabajos, se había resignado a su nueva situación.

Para los que gustan ver parteaguas históricos, el proceso que culminaba el 1 de septiembre podría ser uno de ellos. La instalación de la Cámara de Diputados sin los priistas y la respuesta al informe del presidente por parte de un destacado líder del PRD dio lu- 
gar a enormes expectativas. ${ }^{35}$ A pesar de las aclaraciones de algunos líderes parlamentarios, como los del PAN y el PT, en el sentido de que la alianza para la instalación del Congreso no sería para siempre, ni que todas las alianzas de sus partidos serían en el futuro con los mismos actores, ${ }^{36}$ quedó la impresión en algunos sectores de la opinión pública de que en el Congreso no había cinco fracciones parlamentarias, sino dos: el PRI y la oposición.

Independientemente de expectativas y temores, y de qué tanto eran fundadas o exageradas, la Cámara de Diputados tenía una composición y una actitud nuevas, una pluralidad y una autonomía que no se veía en el país por lo menos en los últimos 60 años. La unidad opositora mostró en esos días la posibilidad de una división de poderes, de un gobierno dividido a nivel federal, y tanto su actitud como la del priismo y del ejecutivo mitigaron los temores de ingobernabilidad: la "crisis constitucional" no se dio.

¿Cuál fue el balance de estas novedades al final del periodo de sesiones,

${ }^{35}$ Entre líneas, pueden verse esas expectativas en la interesante crónica que de este primer periodo de sesiones hizo el periodista Miguel Ángel Granados Chapa, publicada primero en el diario Reforma y luego como libro. Ahí muestra cómo la emoción de los opositores llegó a las lágrimas y a la entonación del himno nacionat cuando lograron instalar la Cámara sin los priistas. Granados Chapa, Vivir, 1998, pp. 12-13.

${ }^{36}$ Son claras al respecto las declaraciones del coordinador de la fracción panista en la LVII Legislatura, Carlos Medina Plasencia, en Minerva Cruz y Alejandro Torres, "Parecen no entender gobierno y PRl la 'nueva realidad': Medina", El Universal, 28 de agosto de 1997. en diciembre de 1997? En los últimos días del periodo, durante la primera quincena de diciembre, la Cámara de Diputados enfrentó importantes decisiones, relacionadas con cuestiones fiscales: la Ley de Ingresos de 1998, el presupuesto de egresos para ese mismo año y un conjunto de leyes conocidas como la Miscelánea Fiscal.

El punto más polémico fue la propuesta de la oposición para disminuir el Impuesto al Valor Agregado de el $15 \%$ vigente, a $12 \%$. Sólo el PRI se oponía. A su juicio, que compartía con el gobierno, la propuesta de los partidos de oposición era oportunista, electorera e irresponsable. ${ }^{37}$ Representaría una disminución significativa de los ingresos gubernamentales y por tanto la necesidad de aumentar otros impuestos, el precio de los servicios públicos, o bien disminuir el gasto del gobierno.

Pero los cuatro partidos de oposición con presencia en la Cámara se mantuvieron en su postura. El cuatro de diciembre votaron por la reducción del IVA, con 252 votos a favor contra 239 de la propuesta priista. Sin embargo, el cambio no procedió pues no fue aprobado por la Cámara de Senadores, con mayoría priista. La Constitución señala que las dos cámaras deben aprobar las iniciativas de ley, en lo que es una especie de "candado" contra el predominio del poder legislativo, que de alguna manera protege al ejecutivo.

La cuestión del iva fue la más polémica en este periodo de sesiones y

${ }^{37}$ Durante todo el periodo, el PRI y el ejecutivo reiteraron esta crítica. Como muestra véanse las declaraciones del presidente Zedillo en $E l$ Universal, 5 de diciembre de 1997, p. 1. 


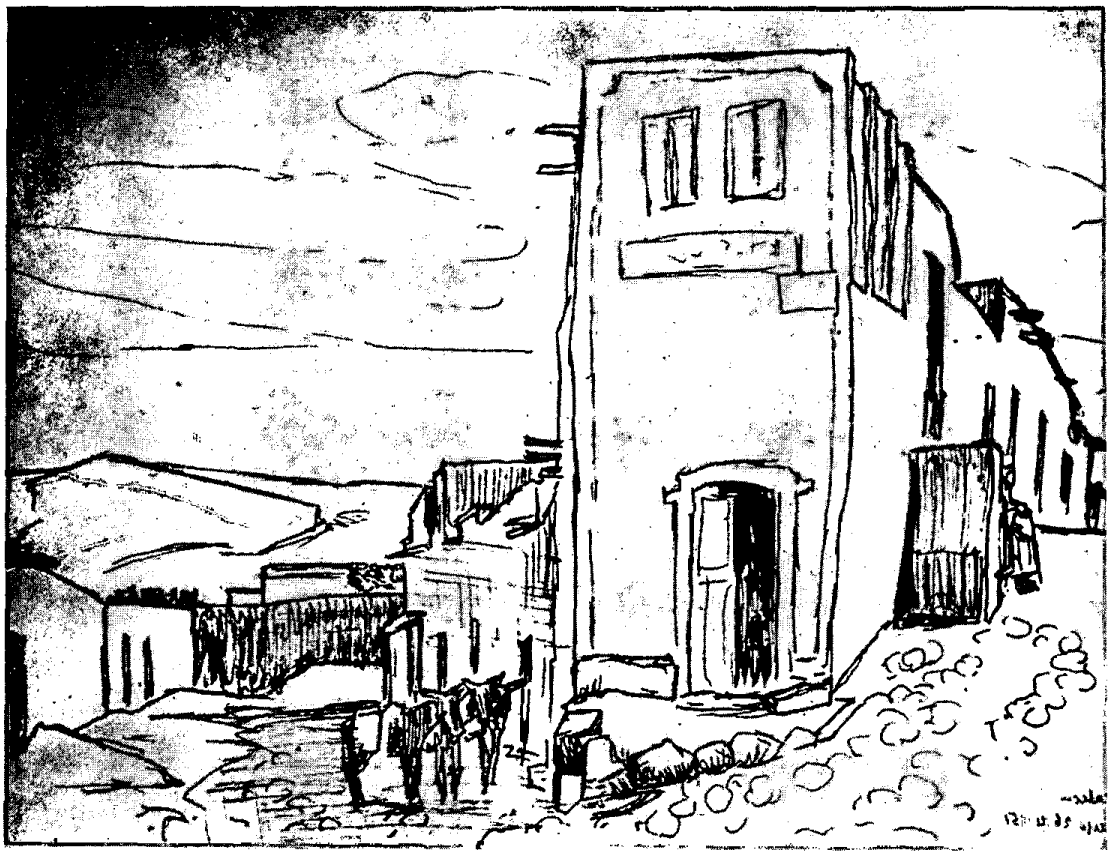

se resolvió mediante el mecanismo institucional señalado: la división del legislativo en dos cámaras, una de ellas, la de senadores, controlada por la mayoría priista, misma que rechazó la reducción de este impuesto.

A pesar de la tensión que vivió la Cámara de Diputados la primera quincena de diciembre, y aparte de la cuestión del IVA, el resto del paquete fiscal se aprobó por consenso de la mayor parte de los grupos parlamentarios. Fue el caso de la cuenta pública de 1996, la Ley de Ingresos para 1998, la Ley de Coordinación Fiscal, entre otras.
La excepción fue el presupuesto de egresos para 1998. Último punto de la agenda legislativa, el PAN votó a favor, junto con el PRI. Fue la ruptura del G-4, el célebre bloque opositor. En Ios discursos que cerraron el fin del periodo de sesiones los líderes de los distintos bloques parlamentarios justificaron su actuación. $^{38}$

${ }^{38}$ Véase "Virtual ruptura del $\mathrm{G}-4$; ruidoso festejo del PRI", "Censura Muñoz Ledo la 'sumisión' del panismo al apoyar las iniciativas económicas del ejecutivo", El Universal, 16 de di- 
Por parte del PaN, su líder, Carlos Medina Plasencia, "dejó en claro que el blanquiazul no es rehén de ningún partido ni del gobierno. 'No somos bloque político, no somos alianza ideológica ni programática, nunca fuimos coalición electoral"', en clara alusión a los perredistas. ${ }^{39}$ Justificó la actuación de su fracción ante las críticas de sus aliados en otras decisiones:

Estamos actuando en política, no en el mundo de las fantasías; luchamos por hacer posible lo necesario en el marco de lo real, en donde tenemos prioridades y buscamos que nuestros principios no se conviertan en dogmas, sino que se abran paso por la fuerza de las ideas y no por la fuerza del antagonismo total que se convierte en obcecación opositora. ${ }^{40}$

Para el perredista Porfirio Muñoz Ledo la actitud del PAN era injustificable, y significaba el resurgimiento del "bloque neoliberal", de la alianza entre el panismo y el gobierno que tantos males, a su juicio, le había traído al país el sexenio pasado:

No quisiéramos ver restablecida en esta Cámara la alianza del bloque neoliberal, el mismo que sirvió a Carlos Salinas para fincar la desmesura de su poder personal, reformar la Constitución a su arbitrio, paralizar, privatizar y corromper el interés público, así como debilitar.dramáticamente a la nación frente al extranjero.

ciembre de 1997, véase también Granados Chapa, Vivir, 1998, pp. 133-136.

${ }^{39}$ El Universal, 1 de diciembre de 1997.

${ }^{40}$ lbid.
Llegaba a su fin el idilio, la alianza de los opositores frente al partido en el gobierno. Se comprobó lo que era más o menos predecible desde el principio: que la alianza opositora, el G-4, difícilmente se mantendría en todas las decisiones legislativas. Que las diferencias entre los cuatro partidos de oposición tarde o temprano fracturarían su coalición. Que seguramente la alianza operaría en algunos puntos, donde intereses y concepciones coincidieran, pero no en otros, en los que alguno de los partidos coincidiera más con el PRI que con los otros opositores.

Pero que la alianza antiPRI se haya desvanecido no quiere decir que no hubo cambios importantes en el Congreso. El partido en el poder no pudo ya imponer sus decisiones, con excepción de la cuestión del IVA. Para lograr el apoyo del PaN y de otros particlos (recordemos que la mayoría de las decisiones sobre el paquete fiscal se aprobaron por consenso de la mayoría de las fracciones), tuvo que considerar otros intereses y otros puntos de vista.

Nunca antes, por otro lado, los asuntos de la Cámara habían sido tan públicos, habían tenido tanta atención de parte de los medios de comunicación y de la población políticamente activa del país. Si bien la nueva legislatura no significó el fin del PRI, sí dio lugar a un cambio notable en su conformación, dinámica y presencia en la vida pública nacional.

\section{LA REFORMA ELECTORAL DE 1996}

En su primer discurso como presidente de México, Ernesto Zedillo anunció 
su pretensión de realizar una reforma electoral "definitiva". ${ }^{41}$ El adjetivo llegó a ser motivo de sorna: en esta vida, se decía, nada hay definitivo, menos una ley electoral. Pero en el contexto político mexicano el término tenía sentido.

El reformismo electoral fue una de las características centrales del sistema de partido hegemónico en México. ${ }^{42}$ Desde la reforma electoral de 1946 , no hubo sexenio sin reformas a la legislación que normaba las elecciones mexicanas. En el sexenio más reciente, durante la presidencia de Salinas (19881994) hubo tres reformas electorales que afectaron a la Constitución y a la ley reglamentaria.

¿Qué es lo que explicaba este reformismo? ¿Era casual? ¿Era un mero accidente en la vida electoral mexicana? ¿Era, por el contrario, parte sustancial de los mecanismos del sistema? Me inclino a pensar esto último.

Vale la pena recordar el mecanismo del reformismo electoral mexicano. El sistema de partidos en México, caracterizado en términos generales como hegemónico, tenía un género próximo: no era competitivo. Y una diferencia específica: había en él partidos de oposición. El género lo ponía junto a otros sistemas sin competencia electoral, como los de partido único; la diferencia específica los distinguía

${ }^{41}$ Proceso, núm. 944, 5 de diciembre de 1994 , pp. 22-23. El PRD coincide con la idea de una reforma electoral definitiva, que es una "expresión perredista".

¿2 Véase, Molinar, "Costumbre”, 1985. El título de este artículo resume bien las tesis de Molinar sobre las elecciones en México: sus constantes han sido la alquimia (eufemismo por fraude) y la reforma. de éstos y le daba una curiosa peculiaridad.

$Y$ esta peculiaridad es la que explica el reformismo. Mantener una oposición auténtica y dispuesta a perder siempre, es difícil. La legislación electoral trató, con éxito durante varias décadas, de guardar un difícil equilibrio: por un lado mantener el control del proceso electoral para garantizar los triunfos del partido hegemónico; por otro, otorgar concesiones a la oposición para que se mantuviera dentro del juego.

El equilibrio resultó durante décadas, pero es fácil imaginar que se rompería en algún momento: no es posible hacer concesiones indefinidamente sin perder el control. Reforma defnitiva sería precisamente aquella en la que el equilibrio se rompiera. La transición a la democracia se daría cuando la ruptura tuviera un sentido preciso: fin del control del proceso electoral por un solo partido, es decir, fin del partido hegemónico.

Este mecanismo nos muestra, me parece, que la dinámica del sistema permitía, incluso exigía, reformas electorales "no definitivas": que a pesar de que otorgaban concesiones a la oposición mantenían el control del proceso electoral por un solo grupo político. Reforma definitiva no significaba la última reforma, sino ei fin de este equilibrio, el fin del control electoral por un solo partido. El fin del sistema de partido hegemónico y la transición a la democracia al menos en una de sus dimensiones más importantes: la legislación electoral.

¿Significaría el fin de este control el principio de la ingobernabilidad? Ha- 
bía al menos alguna probabilidad hipotética de que esto ocurriera; no sólo porque se trataría de un cambio radical en el sistema de partidos, y por tanto en el sistema político, y todo cambio implica riesgos en la gobernabilidad. También porque el fin del control puede dar lugar al descontrol; puede dejar sueltas a fuerzas políticas y sociales que antes se encontraban encauzadas por el sistema de partido hegemónico.

Al iniciar el sexenio de Ernesto Zedillo, en diciembre de 1994, y a pesar de las tres reformas electorales salinistas, la última realizada apenas en mayo de 1994, los partidos políticos aceptaron la propuesta presidencial de reforma electoral y firmaron el documento titulado Compromisos para un Acuerdo Político Nacional el 17 de enero de 1995.

La legislación electoral vigente era bastante avanzada, en relación con garantizar la imparcialidad de los comicios. Pero había puntos importantes que ajustar. Firmado por los dirigentes de los cuatro partidos con representación en la Cámara de Diputados (Carlos Castillo Peraza del PAN, María de los Ángeles Moreno del PRI, Porfirio Muñoz Ledo del PRD y Alberto Anaya Gutiérrez del PT) y por el presidente Ernesto Zedillo como "testigo de honor", el documento señalaba como "el paso más urgente para consolidar la reforma democrática de México" la reforma electoral. ${ }^{43}$

A pesar del consenso, los cambios legales tardarían 19 meses en llegar. Varias razones explican este retraso,

\footnotetext{
${ }^{43}$ Cito la publicación del documento "Compromisos", 1995, p. 27.
}

que por un lado recuerda la gradualidad de la transición mexicana ${ }^{44}$ y por otro muestra dónde estaban los obstáculos para esa transición. Los dos principales partidos de oposición, el PRD y el PAN, se retiraron dos veces cada uno de la mesa de diálogo instalada para realizar la reforma. Las razones fueron fundamentalmente conflictos políticos locales, casi siempre elecciones que la oposición consideraba fraudulentas.

El Partido de la Revolución Democrática abandonó por primera vez el diálogo para la reforma política en abril de 1995. Argumentaba la falta de voluntad del gobierno para resolver los casos de Tabasco y Chiapas, así como el bloqueo por parte de la fuerza pública de diputados perredistas que trataron de entrevistarse con el presidente de la república. Los casos de Tabasco y Chiapas, ambos estados del sureste mexicano fronterizos con Guatemala, ilustran las dificultades de la reforma electoral que terminaría en 1996.

En Tabasco habían tenido lugar elecciones para gobernador el 20 de noviembre de 1994. Ganó el PRI, con un candidato con notable fuerza local, incluso con presencia nacional: Carlos Madrazo. El PRD, principal oposición y que presentó como candidato a Andrés Manuel López Obrador, uno de sus más importantes líderes nacionales, denunció fraude y realizó diversas movilizaciones en el estado y en la capital del país denunciando la alteración de la elección.

44 Traté de explicar las características de la gradualidad mexicana en Reynoso, "Razones", 1998. 
En junio de 1995 el conflicto tabasqueño cobró una nueva dimensión. Misteriosas manos dieron a los perredistas catorce cajas que contenían diversos gastos realizados por el PRI de Tabasco en la campaña electoral de 1994. Los gastos ascendían a más de 273000000 de pesos, una cantidad insólitamente alta; muy alta incluso si hubiera sido para una elección presidencial a nivel nacional. ${ }^{45}$

No es posible aquí detallar el conflicto tabasqueño. Sólo interesa señalar cómo la política regional se puso en primer plano en la nacional, concretamente en lo que se refiere a elecciones locales. México está dividido en 32 entidades, 31 estados y un Distrito Federal. Cada entidad posee su propio calendario electoral, además de sus propias leyes y autoridades electorales. Las elecciones locales dan lugar a un abigarrado calendario electoral, en el que se suceden elecciones de gobernador, presidentes municipales y diputados locales año con año.

Dichas elecciones permiten una radiografía política más completa del país: muestran que tanto las dificultades como las posibilidades de la transición a la democracia varían de región a región. Específicamente, y volviendo a la reforma electoral anunciada desde diciembre de 1994 y concretada hastä octubre de 1996, es posible afirmar que fue en los procesos electorales locales en donde la realización de la ley encontró sus obstáculos más visibles. En ellos se manifestó el poder de gru-

4s Para un análisis periodístico del llamado Tabascogate, véase Albarrán, "Zedillo", 1995, pp. 18-21, y "Convertir", 1995, pp. 18-23. pos priistas tradicionales, que oponían resistencia a los cambios.

En particular, el caso de Tabasco subrayó un tema de la agenda de reforma electoral: el financiamiento a los partidos políticos y los topes a los gastos de campaña. El tema era prioritario por lo menos desde la elección presidencial de 1994; aun quienes aceptaban el resultado de esa votación, señalaban que las condiciones de la competencia electoral eran notablemente inequitativas: un partido, el PRI, contaba con mucho mayor presupuesto y con un espacio privilegiado en los medios de comunicación. ${ }^{46}$ El Tabascogate mostró que esa inequiclad podía alcanzar proporciones extraordinarias: mientras que el "costo del voto" en la elección de Zedillo (agosto 1994) fue de 18.91 pesos (es decir, por cada voto recibido gastó en su campaña esa cantidad), el "costo del voto" para Roberto Madrazo en Tabasco (noviembre 1994) fue de unos 800 pesos. ${ }^{47}$

En Chiapas el problema no era tanto un conflicto electoral, sino la estrategia del gobierno hacia el Ejército Zapatista de Liberación Nacional, grupo que se levantó en armas contra el gobierno en enero de 1994. Poco después del levantamiento se suspendió la lucha armada y el EZLN inició un accidentado diálogo con el gobierno. Por la vía del PRD el conflicto chiapaneco entró al proceso electoral. No

\footnotetext{
${ }^{46}$.Ése fue el contenido del discurso en el que el candidato de Acción Nacional, Diego Pernández de Cevallos, reconoció el triunfo del PRI, el mismo 21 de agosto de 1994, día de la elección.

${ }^{47}$ Albarrán, "Zedillo", 1995, p. 18.
} 
tendría una influencia decisiva, como sí la tuvo el caso de Tabasco y otros conflictos locales, pero muestra por un lado la importancia que el conflicto chiapaneco mantenía en la política nacional y, más particularmente, la peculiar preocupación del perredismo por ese conflicto.

Además de la denuncia de negligencia gubernamental en los casos de Tabasco y Chiapas, el PRD argumentó para retirarse del diálogo el bloqueo por granaderos a diputados perredistas que trataron de entrevistarse con Ernesto Zedillo. Los diputados vieron en ese acto un mensaje por parte del presidente de que mantendría un "autoritarismo bipartidista", es decir, un trato radicalmente distinto al PAN, supuesto aliado del presidente, y al PRD, supuesto enemigo. ${ }^{48} \mathrm{~A}$ diferencia de los conflictos en elecciones locales, esta denuncia no se repitió, o al menos no ocupó un lugar central en el proceso de reforma aquí analizado.

El PAN por su parte se retira por primera vez de la mesa del diálogo en junio de 1995, después de las elecciones en Yucatán. Ubicado también en el sureste mexicano, este estado tiene características políticas y electorales muy distintas a Tabasco y Chiapas. En él la principal oposición ha sido el PAN, con

48 Mayolo, "Irritados", 1995, p. 20. Esta acusación perredista se basaba en antecedentes: uno inmediato, pues horas antes del bloqueo a los diputados del PRD, el presidente había recibido a diputados del PAN; otros, en el sexenio anterior cuando el entonces presidente, Carlos Salinas, estableció relaciones muy distintas con los dos partidos opositores, pues mientras mantuvo un acercamiento con el panismo hostilizó al perredismo. una fuerte presencia desde fines de los años sesenta (en 1967 ganó la capital del estado). Desde 1993 el presidente nacional del panismo era un yucateco, Carlos Castillo Peraza. Por el PRI contendió un político tradicional, Víctor Cervera Pacheco. En Ias elecciones realizadas el 28 de mayo de 1995 el PRI resultó ganador en la elección de gobernador, mientras el PAN alcanzó el triunfo en las principales ciudades. El Pan alegó fraude, por lo que su Consejo Nacional acordó retirarse del diálogo para la reforma política en una declaración hecha pública el 18 de junio de 1995. En ella se califican las elecciones yucatecas como un "atraco", y el argumento principal fue que en las misma se manifestaron: "síntomas de que el gobierno que suscribió los compromisos para un acuerdo político nacional, o no tiene palabra, o es incapaz de hacerla valer en las circunstancias concretas en que se pone a prueba la voluntad democrática".

El panismo puso dos condiciones para regresar a la mesa del diálogo: solución al problema de Yucatán y nombramiento del director del IFE. En octubre de 1995 no se había cumplido ninguna de las dos, pero la Comisión Permanente del Consejo Nacional instruyó al Comité Ejecutivo Nacional "para que reinicie su participación en la discusión sobre la reforma del Estado". 50

${ }^{49}$ La declaración del Consejo panista se publicó en La Nación, 23 de junio de 1995, p. 1, con el título de "Categórico repudio al atraco en Yucatán: PAN".

so Desplegado publicado en La Nación, 27 de octubre de 1995, 1a. de forros. 
En el ánimo panista seguramente fueron decisivos los triunfos que se le reconocieron en las elecciones locales durante 1995: ese partido pasó de gobernar a 13200000 habitantes a principio de año, a 19900000 en octubre, cuando tomó la decisión de regresar. Concluyó el año, el mejor en la historia del panismo, gobernando a 24700000 habitantes, $30.46 \%$ de la población del país. ${ }^{51}$

Después de todas estas vicisitudes, se realizó la esperada reforma "definitiva" en 1996. Para analizarla tendré en cuenta en primer lugar el criterio de mejorar las condiciones de competencia entre los partidos políticos.

Destaca al respecto lo que se refiere a la composición de la autoridad electoral. Dicha autoridad fue durante décadas uno de los puntos centrales del control sobre los comicios. El partido en el poder mantuvo desde 1946 hasta 1988 una clara mayoría en los miembros con derecho a voto en la Comisión Federal de Vigilancia Electoral que después se llamó Comisión Federal Electoral.

En 1991, ya en el Consejo General del IFE, la presencia del "bloque en el poder" (los miembros del Consejo con derecho a voto que votaban a favor del partido en el poder) empezaron a disminuir, hasta llegar a la elección presi-

51 Datos en La Nación, 24 de noviembre de 1995. El presidente panista, a pregunta expresa de por qué habían retornado al diálogo si no se había resuelto el problema en Yucatán, señaló que lo hicieron porque si bien no se había resuelto, tampoco se habia repetido. dencial de 1994 donde sólo tenían tres de once votos, 27.27 por ciento. ${ }^{52}$

La reforma de 1996 redujo este porcentaje a cero. Los "dueños" del Consejo General, o al menos de las votaciones en el mismo, pasaron a ser nueve consejeros electorales, todos sin militancia partidaria. Los partidos políticos, sea a través de sus representantes o por medio de sus legisladores, quedaron con presencia en el Consejo, pero sólo con $\mathrm{voz}$, sin derecho a voto.

No fue el único cambio importante. Por primera vez en la historia contemporánea del país, el poder ejecutivo no tenía presencia en el organismo electoral. Hasta 1996 el secretario de Gobernación presidía al Consejo General del IFE; a partir de ese año no hay presencia del ejecutivo.

Los nueve consejeros son elegidos por la Cámara de Diputados con una mayoría calificada de dos terceras partes. El presidente del Consejo es electo entre ellos por el mismo procedimiento. ${ }^{53}$

Volvamos al polémico adjetivo de esta reforma, "definitiva". En cuanto al equilibrio entre control y legitimidad, parece clara la definitividad: no hay control formal por parte del ejecutivo y su partido. En otro aspecto me parece que por el contrario se trata de una fórmula de transición. Se creó un sistema de funcionarios de alto nivel (los

\footnotetext{
$\$ 2$ Para un análisis de la composición de la autoridad electoral de 1988 a 1994 véase Reynoso, "Razones", cuadro 4.

${ }^{53}$ La composición del Consejo Electoral del IFE está en el párrafo III del artículo 41 de la Constitución Política de los Estados Unidos Mexicanos.
} 


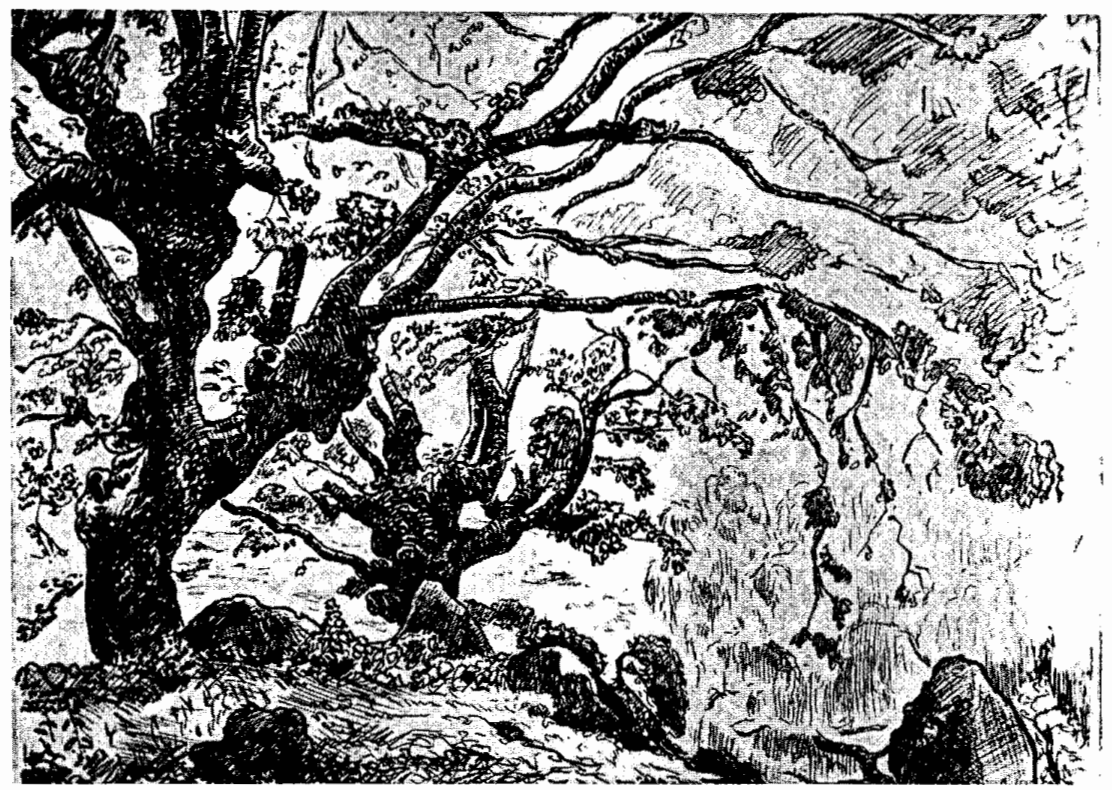

nueve consejeros del IFE tienen las mismas retribuciones que los ministros de la Suprema Corte de Justicia de la Nación) que se suman a un aparato burocrático sumamente costoso.

Las reformas que culminaron, hasta ahora, con la de 1996, hacen que las elecciones mexicanas sean muy caras. Como afirmaron algunos consejeros electorales, no es el costo de la democracia, es el costo de la desconfianza que caracteriza a la vida electoral del país debido al antecedente de partido hegemónico. Es de esperarse que cuando la confianza electoral predomine en el país se tenga una autoridad electoral más simple, más pequeña, más barata.
Otro aspecto fundamental de la reforma es que por primera vez desde 1926 los habitantes del Distrito Federal elegirán a su gobernante. Formalmente no tiene que ver con las condiciones de competencia, pero políticamente sí. El Distrito Federal, la capital del país, ha sido la entidad donde más se ha manifestado la competencia electoral, donde más difícil ha sido el control. En 1988, por poner un ejemplo, el PRI obtuvo ahí solamente $27.3 \%$ de los votos. ${ }^{54}$ Esta competitividad tiene que ver con la distinción

54 Pueden verse los resultados electorales en el Distrito Federal de 1988 a 1997 en Favela $y$ Calvillo, “Elecciones”, 1997, p. 141. 
fundamental de la geografía electoral mexicana durante el periodo de sistema hegemónico: la urbano-rural. En las zonas urbanas el control electoral era mucho más complicado, por lo que la presencia de la oposición era más importante; en las zonas rurales, por el contrario, el control solía ser absoluto, y el PRI alcanzaba votaciones cercanas a 100 por ciento.

Elegir por voto universal y secreto al gobernador del Distrito Federal (que hasta 1997 se le llamaba regente y era designado por el presidente de la república) implicaba una alta probabilidad de triunfo opositor. Así fue, resultando ganador Cuauhtémoc Cárdenas, candidato del Partido de la Revolución Democrática, con lo que cambió de forma importante la correlación de fuerzas entre los partidos políticos, y Cárdenas se convirtió, una vez más, en uno de los más fuertes precandidatos a la presidencia de la república, ahora para el año $2000 .^{55}$

Un tercer punto fue la composición de la Cámara de Diputados. Con la reforma de 1989 un partido político podía obtener hasta 350 diputados, $70 \%$ de la Cámara, con lo que tenía la mayoría calificada suficiente para hacer cambios a la Constitución (66.66\%). Es

\footnotetext{
ss Cuauhtémoc Cárdenas ha sido candidato a la presidencia en 1988 y 1994. En ambos casos perdió, en el primero en una elección muy polémica cuyos resultados no fueron aceptados por Cárdenas $y$ sus simpatizantes. El triunfo del PRD en el D. F. no sólo significó la gubernatura de una de las entidades más importantes del país, sino la mayoría en la Asamblea Legislativa de la capital y un efecto en el resto del país que llevó a este partido a ser la segunda fuerza en la Cámara de Diputados.
}

decir, permitía un claro control del órgano legislativo. En 1993 ese máximo se limitó a 315 diputados (63\% de la Cámara). En 1996 se limitó todavía más: a 300 diputados. ${ }^{56}$

A la restricción anterior se añade otra:

en ningún caso, un partido político podrá contar con un número de diputados por ambos principios [mayoría y representación proporcional] que represente un porcentaje del total de la Cámara que exceda en ocho puntos a su porcentaje de votación nacional emitida. $^{57}$

Se exceptúan los casos en que un partido obtenga, vía triunfos de mayoría en distritos uninominales, un porcentaje de votos superior al tope señalado.

La nueva conformación de la Cámara de diputados contenida en las disposiciones señaladas hacen imposible la mayoría calificada necesaria para reformar la Constitución (66.66\%), lo que significa un cambio importante en la historia parlamentaria mexicana, pues por lo menos desde fines de los años treinta y con la excepción de la legislatura vigente entre 1988 y 1991 , una sola fuerza política tuvo con holgura esa mayoría. Pero además hacen difícil una mayoría absoluta (superior a 50\%). La nueva legalidad hace pues más probable el fin del control parla-

${ }^{56}$ Fracción IV del artículo 54 constitucional.

${ }^{57}$ Fracción $\mathrm{v}$ del artículo 54 constitucional. La misma fracción excluía esta norma de los casos en que un partido obtuviera por triunfos de mayoría un porcentaje de diputados superior a $8 \%$ de su votación. 
mentario y el inicio de una nueva época en la Cámara de Diputados en el país.

Una cuestión menor en relación con lo anterior pero con cierta importancia en la tradición electoral mexicana fue la elevación del porcentaje mínimo requerido para que los partidos tengan derecho a la representación proporcional en la Cámara baja: de 1.5 pasó a 2 . Con esto se limita la existencia de los partidos pequeños, que tradicionalmente han sido sospechosos de oficialismo, de aliados del partido en el poder. Esta elevación del piso fue un logro de las principales oposiciones (PAN y PRD).

La composición de la Cámara de Senadores también tuvo cambios. A los 96 senadores que la conformaban (tres por cada entidad, dos de mayoría y uno para la minoría más importante) se añadieron 32 , que serían electos por representación proporcional a partir de las listas que presentaran los partidos a nivel nacional. Esta reforma fue cuestionada por un lado porque rompía la representación paritaria entre las 32 entidades que conforman el pacto federal en México, y también porque daba lugar a una Cámara demasiado grande, de 128 senadores.

En cuanto a sus virtudes, la nueva composición limita la excesiva sobrerrepresentación del partido dominante en esa Cámara, pero no la elimina. Se ha calculado que permite sobrerrepresentaciones de hasta 23 por ciento. ${ }^{58}$

\footnotetext{
58 Becerra Chávez, "Reforma", 1997, p. 28. El cálculo de $23 \%$ de sobrerrepresentación es de José Antonio Crespo, citado por Becerra, donde presenta un cuadro (núm. 2) sobre los
}

En lo referente a la justicia electoral la reforma de 1996 trajo cambios poco espectaculares pero sin duda profundos. El poder judicial federal estuvo excluido de lo electoral desde 1949. La reforma electoral de ese año excluyó a la Suprema Corte de Justicia de la Nación de los comicios. En interpretación de Juan Molinar, dicha exclusión

se originó en los efectos que entre 1945 y 1946 tuvieron los recursos interpuestos ante la Corte por diversas organizaciones políticas, tanto locales como federales, y como la Corte no siempre falló en el sentido que convenía al PRI, y cuando lo hizo fue en medio de intensos debates entre ministros, el gobierno decidió tratar de aislarla de los procesos electorales. ${ }^{59}$

En esa misma época, en la segunda mitad de los cuarenta, se consolida el sistema de partido hegemónico. La exclusión de la Suprema Corte de las elecciones fue parte importante de esa consolidación.

En 1996 la máxima autoridad judicial del país vuelve a lo electoral. Por un lado se reforma el artículo 105 constitucional para que la Suprema Corte pueda conocer y resolver sobre la inconstitucionalidad de las leyes electorales federales y locales. Por otro se reforma el Tribunal Electoral (antes Tribunal Federal Electoral) para integrarlo al poder judicial de la federación. Dicho tribunal es el encargado de conocer y resolver sobre las accio-

niveles de sobrerrepresentación, notablemente altos, que el PRI ha tenido en esa cámara entre 1988 y 1994.

${ }^{59}$ Molinar, Tiempo, 1991, p. 37. 
nes de las autoridades electorales así como sobre los derechos electorales de los ciudadanos. ${ }^{60}$

No se trata de un cambio espectacular, con consecuencias vistosas en el corto plazo. Pero sí de un cambio de fondo. Da mayor solidez jurídica tanto al entramado legal, incluidas las leyes electorales de las 32 entidades federativas, como a los procesos electorales. No es un dato menor que, después de una ausencia de 47 años, el poder judicial de la federación vuelva a participar en las elecciones. Como lo señaló Vázquez Alfaro: "Por fin, después de mucho tiempo[...]el poder judicial será garante de la constitucionalidad y de la legalidad de uno de los procedimientos connaturales a la democracia contemporánea: las elecciones". ${ }^{61}$

La reforma electoral de 1996 tocó también uno de los temas más polémicos a partir tanto de las elecciones federales de 1994 como de algunos procesos locales, el de Tabasco particularmente: la equidad en el financiamiento de los partidos. Se amplió notablemente lo que ahora es la fracción II del artículo 41 constitucional, en donde se señala con más énfasis la equidad entre partidos. ${ }^{62}$ Se precisa cómo se repartirá el financiamiento público a los mismos: del total destina-

${ }^{60}$ Franco, "Bienvenida", 1996.

${ }^{61}$ Vázquez, "Justicia", 1996, p. 30.

${ }^{62}$ Anteriormente sólo se señalaba que los partidos deberían contar, "en forma equitativa", con elementos para sus actividades. Ahora se dice que "La ley garantizará que los partidos nacionales cuenten de manera equitativa con elementos para llevar a cabo sus actividades". Art. 41 constitucional; cursivas mías. do, $30 \%$ se distribuirá en forma equitativa entre todos, y el restante $70 \%$ en proporción al número de votos obtenido por cada uno en la elección anterior. Se menciona además el derecho de los partidos al uso permanente de los medios de comunicación. Y finalmente el punto que rompió el acuerdo: se fijarán límites a los gastos de campaña y sanciones al incumplimiento de las normas.

La cuestión de los límites a los gastos de campaña de los partidos quedó señalada en el texto constitucional. La ley reglamentaria precisa las cantidades. Ahí los partidos no se pusieron de acuerdo. Mientras las reformas constitucionales fueron aprobadas por unanimidad, las reformas a la ley reglamentaria (el Código Federal de Instituciones y Procedimientos Electorales), sólo las aprobó la fracción priista. El consenso se rompió porque el PRI pretendió, y logró, un tope a los gastos de campaña que la oposición consideró demasiaclo alto. Al irse solos, los 282 diputados priistas no sólo aprobaron el límite para los gastos de campaña rechazado por la oposición por demasiado alto, sino que dieran marcha atrás en otros puntos en los que ya habían encontrado consenso con la oposición. ${ }^{63}$

Esta ruptura suscitó, obviamente, fuertes críticas de la oposición. Significó un fuerte golpe contra el largo proceso de diálogo para llevar a buen término una reforma. Sin embargo, los cambios constitucionales quedaron

${ }^{63}$ Un breve análisis de estos puntos se encuentra en "Bitácora electora", Voz y Voto, núm. 46, dic. de 1996, pp. 47-48. 
ahí, con avances notables, algunos ya señalados aquí, otros, como la obligación de que el listado nominal lleve la fotografía de los ciudadanos, disposición que incrementa las garantías de transparencia electoral, fueron incorporados a la ley reglamentaria, a pesar de la ruptura del consenso.

Vale la pena comentar dos aspectos importantes de la reforma, que no están en el eje que ha guiado el análisis aquí presentado, el equilibrio entre legitimidad y control por un solo partido. Me refiero en primer lugar a los requisitos para que nuevos partidos obtengan su registro y a la elevación del tope mínimo de votación para que los partidos que ya cuentan con registro oficial lo mantengan; en segundo a las posibilidades de coalición. Ambos aspectos han sido considerados como parte de un nuevo proteccionismo electoral, como el paso de un monopolio a un oligopolio. ${ }^{64}$

Tanto los requisitos para el registro de nuevos partidos como para la realización de coaliciones siguen siendo difíciles de cumplir. Situación que favorece a los partidos que ya tienen registro, en particular a los tres mayores (PRI, PAN y PRD), que están muy por arriba del nuevo límite que exige la ley $(2 \%)$. Aquí se puede hablar de "control", o de "proteccionismo" electoral, ya no para proteger a un partido, sino a tres o cuatro. De cualquier manera parece claro que, en términos electorales, la diferencia cualitativa está entre uno y más de uno: entre la ausencia de alternancia o su posibilidad. Por otro 1998.

"4. Romero, "Oligopolio", 1996; "Nuevo", lado, los costos de abrir el sistema electoral a cualquier grupo que quiera participar en elecciones, y que para cllo exija presupuesto público, serían muy altos: abrirían las puertas al oportunismo político y no habría presupuesto para financiarlo.

La reforma de 1996 incorporó en la Constitución la obligación de que las leyes electorales locales se ajusten a los principios básicos de la Carta Magna. Con esta disposición se incorporan las preocupaciones de la oposición en relación con las dificultades de algunos comicios locales, como los ya mencionados de Tabasco y Yucatán. Ciertamente es un cambio formal, pero al menos incorpora a la máxima ley del país la preocupación por los procesos electorales locales, en donde la transición a la democracia en México ha tenido por un lado importantes obstáculos, pero por otro sus más importantes logros. ${ }^{65}$

Un comentario final. He elegido, de entre diversas posibilidades de interpretación, a aquella que explica el reformismo electoral mexicano como un equilibrio entre la necesidad de legitimar al sistema frente a los partidos opositores, y la necesidad de mantener el control del mismo por el partido en el poder. Esta interpretación, en mi opinión, toca lo fundamental de un sistema de partido hegemónico y

${ }^{65}$ Como puede verse en el apartado de este artículo sobre gobiernos divididos, la alternancia se ha dado ya en varios estados de la federación, y la oposición gobierna, ya a fines de 1997, varias de las más importantes ciudades del país, entre ellas la capital, gobernada por el PKD a partir de este año. 
de la transición a la democracia. No abarca desde luego todo; hay temas de la legislación que quedan fuera de esta dinámica.

Hay razones para pensar que el citado equilibrio ya se rompió: que no hay un partido que controle el proceso electoral. No es fácil fechar esta ruptura, por la dinámica misma del equilibrio se trata de un proceso gradual. Pero parece claro que la reforma electoral de 1996 significó un paso fundamental en el fin del peculiar equilibrio mencionado. Fin que le da cierto contenido a la expresión "reforma electoral definitiva".

Por supuesto que no será la última reforma electoral en el país. Hay necesidad de ajustar la legislación en diversos temas. A largo plazo seguramente se requerirá de una legislación más simple, y de un aparato electoral más barato. Pero serán reformas en un sentido notablemente distinto al que marcó el reformismo electoral mexicano en las largas décadas del sistema de partido hegemónico.

¿Qué decir sobre la gobernabilidad en relación con la ruptura del equilibrio entre control y legitimidad? El fin de este equilibrio significaría el fin del sistema de partido hegemónico, y como todo fin de sistema implica riesgos de gobernabilidad. Que el control electoral ya no es el de antes queda de manifiesto tanto en la conformación de los organismos electorales como en los resultados de las elecciones. Ambos han sido analizados en este artículo. Los organismos electorales ya no son controlados por una fuerza política; la conformación de la Cámara de Diputados, producto de la elección del
6 de julio de 1997, en la que ningún partido tiene la mayoría absoluta, nos habla bien del fin del control electoral o bien de su limitación a ciertas regiones del país.

$Y$ todo parece indicar que no hay problemas de gobernabilidad. Ni en el ámbito local, en los múltiples y diversos casos de gobiernos divididos, ni en el ámbito federal. En el primer periodo de sesiones de Cámara sin mayoría partidaria corrieron las expectativas, los golpes y los insultos; pero nada que pueda considerarse síntoma de ingobernabilidad.

Ésta se da en algunas regiones del país con el resurgimiento de la guerriila. Pero son zonas aisladas geográficamente y marginadas social y económicamente. Y más en relación con nuestro caso: son regiones en las que no se ha dado la transición electoral entendida como una mayor pluralidad y competencia entre partidos.

\section{CONCLUSIONES}

He tratado de dar cuenta de algunos de los más importantes cambios de la política mexicana en la última década, de los riesgos que implican para la gobernabilidad, y del balance que es posible hacer hasta ahora.

Tres aspectos de la realidad política han sido considerados: los nuevos actores o los nuevos papeles para viejos actores; la aparición de "gobiernos divididos", primero en el ámbito regional y luego en la Cámara de Diputados federal, y la reforma política de 1996 que dio lugar a un nuevo marco legal para las elecciones mexicanas. 
En los tres aspectos los cambios han sido notables, de tal manera que en 1998 los mexicanos tenemos un sistema de partidos notablemente distinto al que teníamos antes de 1988 . Literalmente se trata de un cambio de sistema. Y como todo cambio importante, el que ha vivido la política mexicana implica riesgos de gobernabilidad.

El éxito de la candidatura de Cuauhtémoc Cárdenas, y sobre todo la continuidad del grupo o grupos políticos que se aglutinaron en torno a esta figura, y que dieron lugar al Partido de la Revolución Democrática, significaron no sólo la aparición de un partido más. Rompieron una regla de oro del sistema hegemónico, que exigía la unidad de la clase política en el poder. Aunque el PRI ha estado lejos de desmoronarse, y por el contrario ha mantenido su unidad, ya es posible tener éxito político y electoral fuera de ese partido.

Los gobiernos divididos, entendidos como aquellos en los que el partido en el poder ejecutivo no tiene la mayoría en el poder legislativo, rompieron también con una característica del sistema político mexicano. El cambio apunta al fin del control sobre los congresos legislativos, a una creciente importancia de éstos, a un incremento en la división de poderes.

Finalmente, el contar con organismos electorales autónomos y otros aspectos mencionados sobre la reforma electoral de 1996, también constituyen novedades radicales respecto a la función de la política mexicana durante las décadas del sistema de partido hegemónico.
El sistema de partidos, entendido como todo el entramado legal y político electoral, ya no es el mismo. ¿Se afectó la legendaria gobernabilidad mexicana, que le dio a México un lugar de excepción en América Latina?

Aunque los problemas para la sociedad mexicana en la última década han sido múltiples y graves, sobre todo en la economía y la seguridad pública, la política no parece mostrar signos de crisis de gobernabilidad. Entendida como la incapacidad del gobierno para ejercer sus funciones, la ingobernabilidad tendría quizá sus manifestaciones más importantes en lo que se refiere a la definición weberiana del Estado: el monopolio de la violencia legítima. Ciertamente el Estado mexicano no ejerce ese monopolio en algunas regiones del país, particularmente en la región de Chiapas controlada por el Ejército Zapatista de Liberación Nacional y algunas regiones de los estados de Guerrero y Oaxaca con presencia del Ejército Popular Revolucionario. Pero la importancia de este control guerrillero es sólo simbólica; se da en porciones muy pequeñas del territorio nacional, cuya importancia económica y política es poco significativa.

El problema de la seguridad pública se ha agravado notablemente en los últimos años. Algunos, concretamente Gabriel Zaid, han relacionado este agravamiento con la transición a la democracia, al sugerir que grupos desplazados del poder político han enfocado sus esfuerzos hacia actividades ilícitas. Ciertamente es razonable pensar que los altos grados de delincuencia no obedecen a acciones espontáneas de 


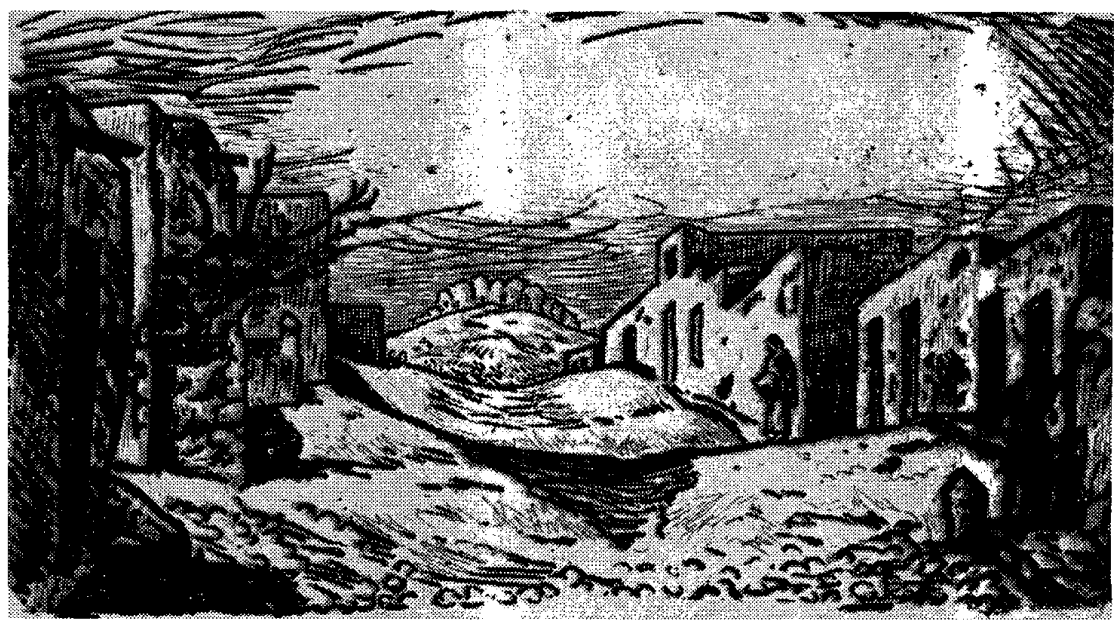

desempleados, sino a grupos poderosos y bien organizados, como ha insinuado Zaid. Pero no es claro, o no hay evidencia empírica, de que detrás de ellos estén grupos desplazados del poder político.

Sin subestimar la importancia del problema, no parece que la delincuencia en México afecta la gobernabilidad. Siendo optimistas, es posible plantear que incluso la competencia democrática por el poder contribuirá notablemente a disminuir el problema. La alternancia en el poder en 1997 en el Distrito Federal, la entidad con mayores problemas de seguridad pública, puede ser un estímulo para las autoridades para atacar el problema.

En cuanto a la situación económica, el país vivió en 1995 su peor crisis desde 1929 Con el agravante de que fue una crisis sobre la crisis. Los mexicanos que se incorporaron a la vida pública en 1976 han vivido permanentemente en crisis económicas. Dejan¿do de lado la cuestión de cuál es el punto a partir del cual una crisis económica significa ingobernabilidad, parece claro que si bien la transición política en México no ha resuelto esta dinámica de crisis, tampoco las ha causado; que viene desde antes y obedece a otros factores, entre los cuales está la nueva dinámica del capital financiero internacional.

Dejando de lado las problemáticas más graves y más visibles, y centrándonos en las transformaciones político-electorales analizadas en este texto -el nuevo sistema de partidos, la generalización de los gobiernos divididos, y el nuevo marco jurídico electoral-me parece que no hay señales de ingobernabilidad; que estos cambios que han transformado la realidad electoral y partidaria del país se han dado 


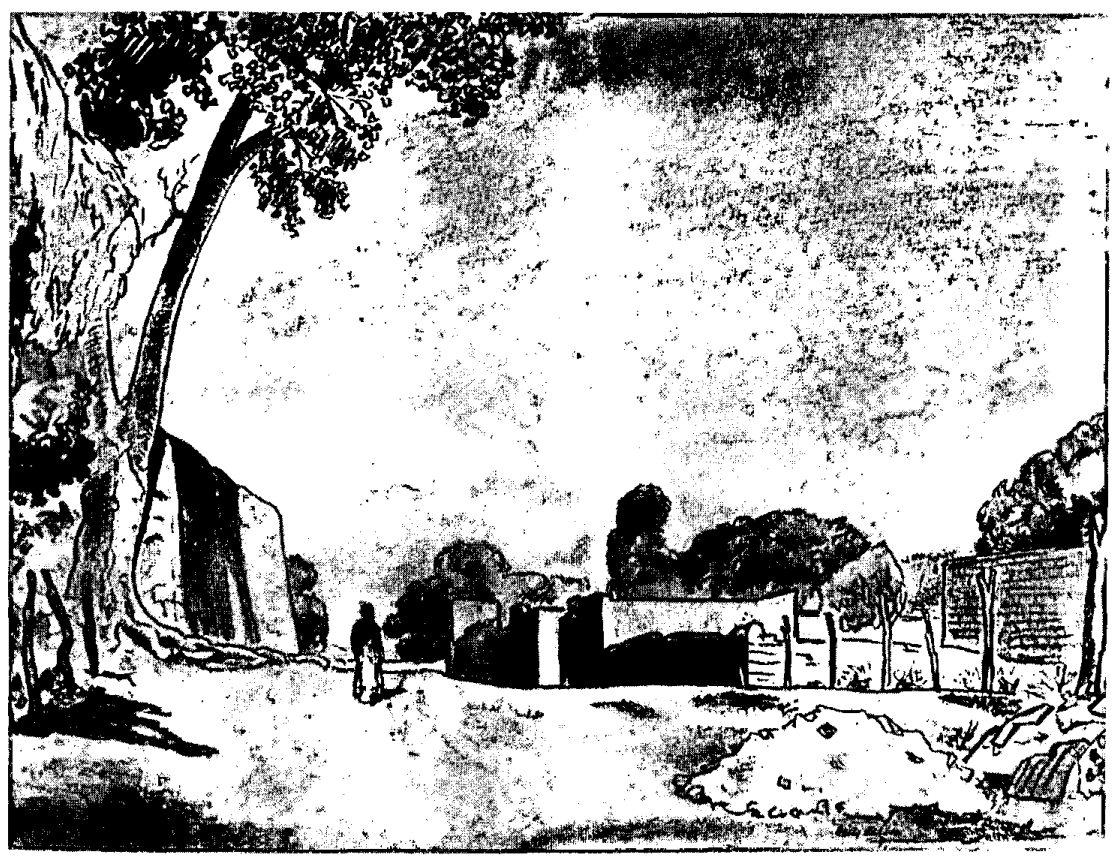

de manera pacífica y civilizada; que se ha pasado sin rupturas ni violencia de una institucionalidad política a otra; que quienes conocieron la política mexicana en las largas décadas que van de los años treinta a los ochenta, no la reconocerían ahora, al menos en el tema que nos ocupa: partidos, elecciones, relación entre poderes ejecutivos y legislativos.

Se ha tratado de un cambio gradual y $\sin$ rupturas, debido en parte a la peculiaridad del sistema de partido hegemónico que, a diferencia de los sistemas de partido único, siempre realizó elecciones y siempre tuvo parti- dos de oposición. Quisiera destacar que la gradualidad del cambio tuvo que ver también con el federalismo electoral mexicano, que permanentemente tiene elecciones locales de gobernadores, congresos locales y municipios. El gradualismo de la transición política mexicana se da así no sólo en el tiempo, sino en el espacio. Antes de cambios políticos a nivel nacional, se han dado en el país multitud de cambios regionales. Alternancia, gobiernos divididos, derrotas y recuperaciones del otrora partido hegemónico se dieron primero en las partes, antes que en el todo. 
Que algunos de los viejos actores sigan ahí no debe confundirnos y hacernos pensar que las cosas no han cambiado. El escenario es otro; los papeles son distintos, aunque algunos de los viejos nombres sigan siendo los mismos. El sistema ya cambió.

Todo esto, reitero, a nivel del sistema de partidos y las elecciones. Algunos dirán que cuestiones como la cultura, las redes del poder, las prácticas políticas, son estructuras de larga duración y que no cambian tan fácilmente. Que el porfiriato, o las estructuras profundas que se expresaron bajo ese régimen, estuvieron presentes a lo largo de este siglo y lo estarán en el que viene. Que son contenidos que pueden convivir bajo distintas formas políticas. Que la democracia electoral es sólo una forma que no afecta lo sustancial de la cultura y las prácticas políticas mexicanas. Puede que sí, puede que no. En todo caso, aquí estará una de las polémicas que deberá enfrentar la ciencia política para el caso mexicano.

E-mail: reybrito@puebla.podernet.com.mx

\section{DOCUMENTOS}

-Partido Acción Nacional, "Compromisos para un Acuerdo Político Nacional", La Nación. Órgano oficial del PAN, 20 de enero de 1995 , p. 27.

-Partido Acción Nacional, "Compromiso Nacional por la Legitimidad y la Democracia", publicado en diarios de circulación nacional, 17 de noviembre de 1988.

-Partido Acción Nacional, Abel Vicencio Tovar, "Discurso pronunciado el 1 de diciembre de 1988 ante el Congreso de la Unión, para fijar la posición del PAN frente al titular del ejecutivo federal que tomó posesión ese día", Palabra de Acción Nacional, núm 8, abril-junio de 1989, pp. 1420.

-Mesa de Trabajo Permanente para la Discusión de la Reforma Política del Estado, "Agenda para la discusión de la reforma política del Estado", 15 de mayo de 1995, publicada en Voz y Voto. Política y Elecciones, revista mensual, núm. 28 , junio de 1995, México, pp. 53-54.

\section{BIBLIOGRAFIA}

-Albarrán de Alba, "De Zedillo a Madrazo: en documentos el derroche, el acarreo, la compra de voluntades y el soborno a la prensa, durante las campañas del PRI", Proceso, núm. 971, 12 de junio de 1995, pp. 18-21.

- "Convertir el escándalo de Tabasco en palanca para el avance democrático: los consejeros Creel y Ortiz Pinchetti", Proceso, núm. 972, 19 de junio de 1995, pp. 18-23.

-Alcocer, Jorge, "El nuevo paseo de la reforma", Vozy Voto. Política y Elecciones, revista mensual, núm. 28 , junio de 1995 , México.

-Aziz Nassif, Alberto, "Alternancia primero, gobierno dividido después: el caso de Chihuahua, 1991-1996" en Lujambio, Poder, 1996.

-Becerra Chávez, Pablo Javier, "La reforma electoral de 1996" en Cansino, Después, 1997.

-Cansino, César (coord.), Después del PRI. Las elecciones de 1997 y los escenarios de la transición en México, Centro de Estudios de Política Comparada, México, 1997.

-Cosío Villegas, Daniel, El sistema político mexicano: las posibilidades de cambio, Joaquin Mortiz, México, 1976.

-Dutrénit, Silvia, Huellas en las transiciones. Partidos y elecciones en América Latina, Instituto Mora, México, 1998. 
-Favela, Alejandro y Miriam Calvillo, "Elecciones locales de 1997: resultados y tendencias" en Cansino, Después, 1997.

-Franco S., J. Fernando,"Bienvenida al litigio", Voz, y Voto, Política y Eleciones. diciembre de 1996, México.

-Garmendia G., Marina, "Un gobierno dividido fugaz: la historia de la VII Legislatura de Baja California Sur, 1993-1996" en Lujambio, Poder, 1996.

-Granados Chapa, Miguel Ángel, Vivir en San Lázaro. Cien días de una legislatura, Ed. Océano, México, 1998.

-Guillén López, Tonatiuh, "Gobierno dividido en Baja California: integración y dinámica legislativa en el periodo 19891995" en Lujambio, Poder, 1996.

-Hurtado, Javier, "Los gobiernos divididos y las elecciones de 1998 en México", Este País, abril de 1998.

-Lujambio, Alonso (comp.), Poder legislativo. Gobiernos divididos en la federación mexicana, Congreso Nacional de Ciencia Política, UAM/IFE/CNCPAP, MÉxICO, 1996.

-Mayolo López, Fernando, "Irritados por los granaderos, los diputados perredistas alertan contra el autoritarismo bipartidista de Zedillo", Proceso, núm. 965, 1 de mayo de 1995.

-Molinar, Juan, "La costumbre electoral mexicana: entre la reforma y la alquimia", Nexos, núm 85, enero de 1985, México. , El tiempo de la legitimidad. Elecciones, autoritarismo y demo- cracia en México, Cal y Arena, México, 1991.

-Morales M., Rodrigo, "La transición no es fácil", Voz y Voto. Política y Elecciones, revista mensual, núm. 28, junio de 1995 , México.

Pantoja Morán, David, "Gobierno dividido en México: el riesgo de la ineficiencia", Este País, junio 1997.

Reyes Rodríguez, Andrés, "Gobierno dividido y convivencia política en Aguascalientes, 1995-1996" en Lujambio, Poder, 1996.

Reynoso, Víctor Manuel, "Acción Nacional: la prueba de las urnas", El Cotidiano, núm. 65, noviembre de 1994 .

- "Las razones y las formas de una transición gradual" en Dutrénit, Huellas, 1998.

-Rionda, Luis Miguel, "Guanajuato: gobierno dividido y cohabitación partidista, 1991-1996" en Lujambio, Poder, 1996.

-Romero, Jorge Javier, "Oligopolio electoral", Voz y Voto. Política y Elecciones, núm. 46, 1996, México.

- "El nuevo proteccionismo electoral", Voz y Voto. Política y Elecciones, núm. 62, abril de 1998, México.

-Valderrábano, Azucena, Historias del poder. El caso de Baja California, Grijalbo, México, 1990.

Vázquez Alfaro, José Luis, "Justicia electoral", Voz y Voto. Política y Elecciones, revista mensual, núm. 46 , diciembre de 1996, México. 


\section{SECUENCIG}

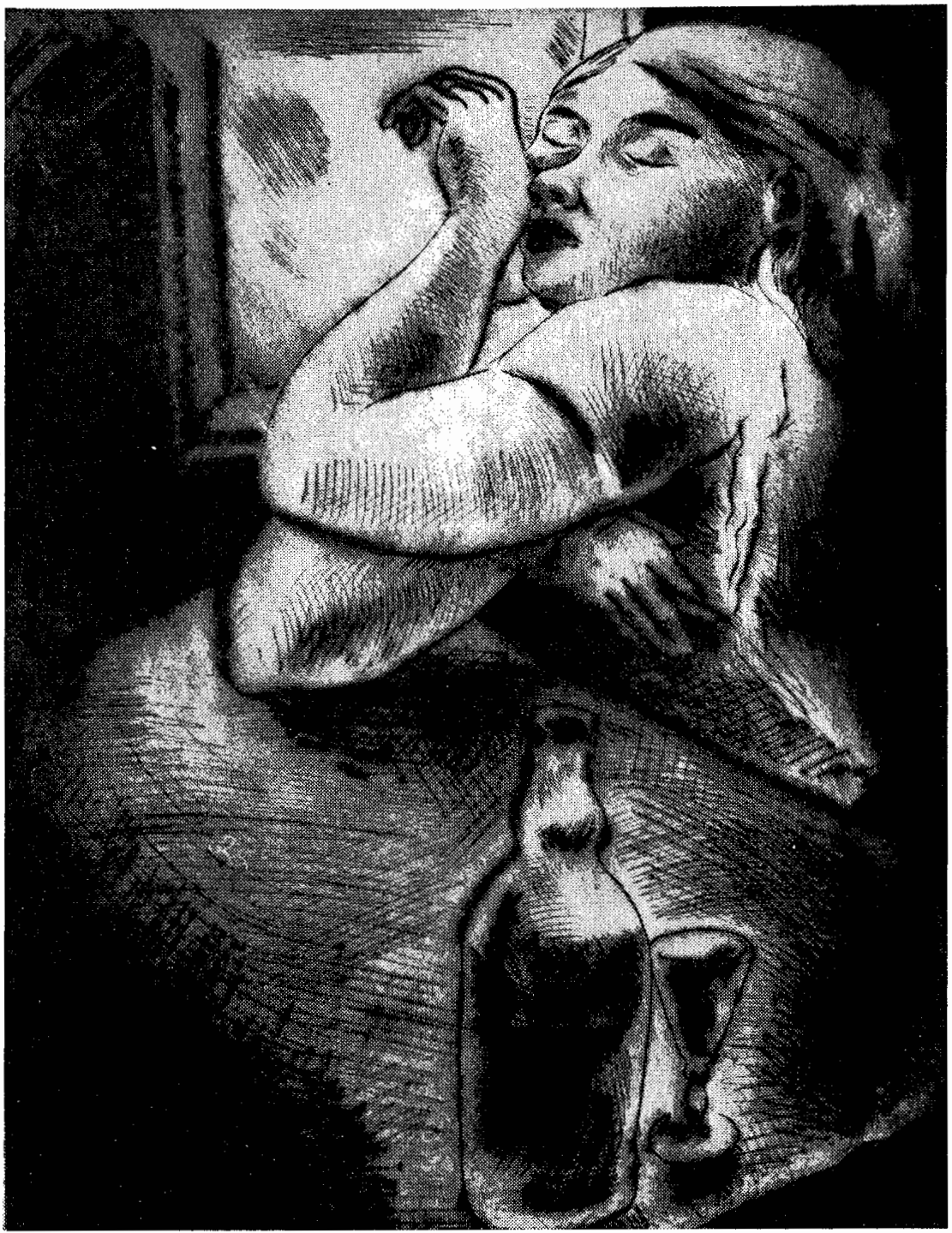

